\title{
Water-Mass Transformations in a Neutral Density Framework and the Key Role of Light Penetration
}

\author{
DANIELE IUdicone \\ Laboratoire d'Océanographie et du Climat: Expérimentations et Approches Numériques, Unité Mixte de Recherche 7159 \\ CNRS/IRD/UPMC/MNHN, Institut Pierre Simon Laplace, Paris, France, and Stazione Zoologica "Anton Dohrn," Naples, Italy \\ GURVAN MADEC \\ Laboratoire d'Océanographie et du Climat: Expérimentations et Approches Numériques, Unité Mixte de Recherche 7159 \\ CNRS/IRD/UPMC/MNHN, Institut Pierre Simon Laplace, Paris, France, and National Oceanography Centre, \\ Southampton, United Kingdom \\ Trevor J. McDougall \\ CSIRO Marine and Atmospheric Research, Hobart, Tasmania, Australia
}

(Manuscript received 21 September 2005, in final form 12 September 2007)

\begin{abstract}
A new formulation is proposed for the evaluation of the dianeutral transport in the ocean. The method represents an extension of the classical diagnostic approach for estimating the water-mass formation from the buoyancy balance. The inclusion of internal sources such as the penetrative solar shortwave radiation (i.e., depth-dependent heat transfer) in the estimate of surface buoyancy fluxes has a significant impact in several oceanic regions, and the former simplified formulation can lead to a $100 \%$ error in the estimate of water-mass formation due to surface buoyancy fluxes. Furthermore, internal mixing can also be overestimated in inversions of in situ data when the shortwave radiation is not allowed to be penetrative.

The method examines the evolution equation of neutral density via the tendencies of potential temperature and salinity. The neutral density framework does not require the choice of a reference pressure and thus, unlike previous approaches that consider potential density, it is well suited for examining the whole open-ocean water column.

The methodology is easy to implement, particularly for ocean numerical models. The authors present here its application to a long simulation made with an ice-ocean global model, which allowed the method to be validated.
\end{abstract}

\section{Introduction}

The density gradients associated with the global thermohaline circulation are created at the ocean surface and, to a minor extent, at the bottom boundaries by buoyancy fluxes that force large diapycnal fluxes. Dianeutral mixing due to external mechanical power consumption alters these gradients, thus supplying the potential energy needed to maintain the circulation. The nonlinear nature of the equation of state for seawater also produces dianeutral fluxes that need to be taken into consideration. Despite its importance, a complete

Corresponding author address: Daniele Iudicone, Stazione Zoologica “A. Dohrn," Villa Comunale 1, 80121 Naples, Italy.

E-mail: iudicone@szn.it picture of dianeutral fluxes in the ocean is not yet available (Wunsch and Ferrari 2004).

The lack of oceanic measurements and of an accurate theoretical framework is not the only reason for this incomplete picture of how water masses are formed and transformed. Diagnostic methods for water-mass formation based on buoyancy balance have been developed only recently, even for numerical models. The classical method for estimating the water-mass formation rate is generally the thermodynamic method, which is based on divergence of the air-sea flux transformation (e.g., Walin 1982; Tziperman 1986; Speer and Tziperman 1992), extended to take mixing into account (Garrett et al. 1995; Marshall et al. 1999; Nurser et al. 1999). The local subduction rate (e.g., Stommel 1979; Marshall et al. 1993; Blanke et al. 2001, 2002), calcu- 


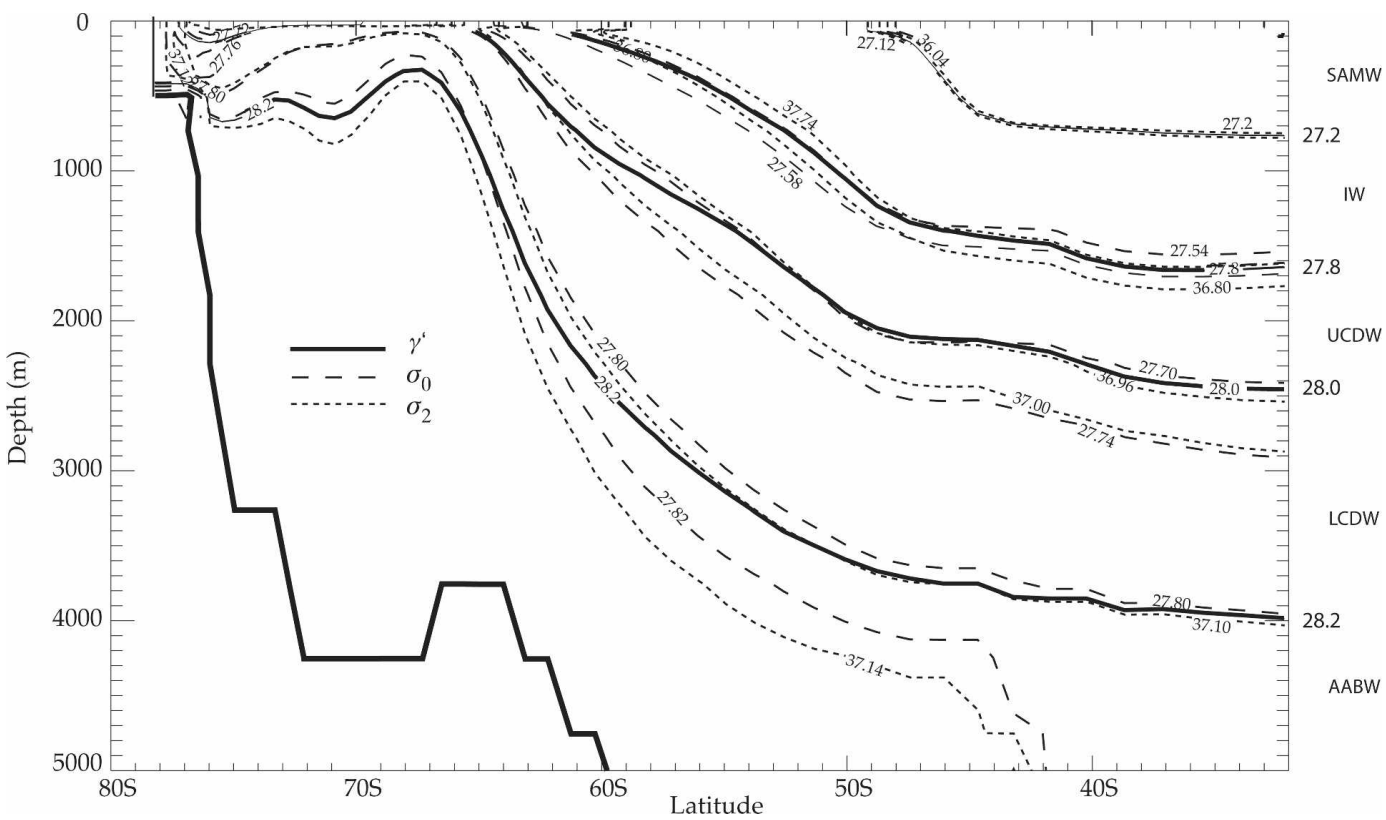

FIG. 1. Austral spring meridional section $\left(175^{\circ} \mathrm{W}\right)$ of the ice-ocean model density field. Note the large discrepancies among the isosurfaces for neutral densities larger than $27.2 \gamma^{\prime}$. [See Table 1 for water-mass definitions and appendix $\mathrm{C}$ for the model configuration. Note that to classify water masses with neutral density we used the Jackett and McDougall (1997) software whose output is defined here as $\gamma^{\prime}$. In fact, it is a practical unit for $\gamma$ with values $\left.O\left(20-30 \mathrm{~kg} \mathrm{~m}^{-3}\right)\right]$.

lated kinematically and integrated between isopycnals from one boundary to the other, should equal the formation rate in the absence of diffusive processes (Marshall et al. 1999; Large and Nurser 2001).

This paper is an attempt to generalize the classical approaches, in particular the one in Marshall et al. (1999), by the use of neutral densities and the inclusion of internal sources/sinks of buoyancy that were not previously considered. There are, in fact, two main drawbacks in the current methods. The first is the use of surface-referenced potential density (e.g., Large and Nurser 2001; Marshall et al. 1999), which is clearly not suitable for the analysis of domains that include deep layers (Fig. 1). Also, the transports due to purely internal nonlinear processes such as cabbeling or thermobaricity (as described by McDougall 1987b) cannot be properly evaluated on potential density surfaces. This problem can be overcome using a more general density variable, namely, neutral density (McDougall 1987a; Jackett and McDougall 1997), at present widely used for the analysis of oceanic data. We will show in this study that the use of the standard approach (e.g., Tziperman 1986) but using neutral density surfaces (e.g., Sloyan and Rintoul 2001) is not strictly correct. A more accurate formulation is developed here that is fortunately quite easy to implement.

The second improvement on current practice is the treatment of the solar shortwave contribution to nearsurface heat fluxes. In contrast to the other components of the air-sea interaction, the solar shortwave radiation penetrates into the subsurface layers, with an exponential decay having an $e$-folding depth varying from less than 1 to $\sim 20 \mathrm{~m}$ (e.g., Mobley 1994), depending on the wavelength and the transparency or water type. This depth-dependent aspect of the solar radiation has not been considered in previous analyses (e.g., Large and Nurser 2001); the implicit assumption previously has been that the heating occurs only within the mixed layer. This is not generally the case (Fig. 2; see also Ohlmann et al. 1996) and, especially at midlatitudes in summer or in the equatorial and tropical upwelling systems, its impact, which depends also on water turbidity (Mobley 1994), is not negligible (e.g., Miller et al. 2003; Marzeion et al. 2005). Therefore, we also include that effect in the diagnostics of dianeutral fluxes presented here.

In this paper, besides the methodology, we present its application to the fields produced by an ice-ocean coupled model. The aim is first to validate the methodology and then to illustrate the impact of the new theory on the estimate of the water-mass transformations in some prominent cases. The paper is organized as follows: section 2 is devoted to the presentation of the method; in section 3, the impact of the inclusion of 

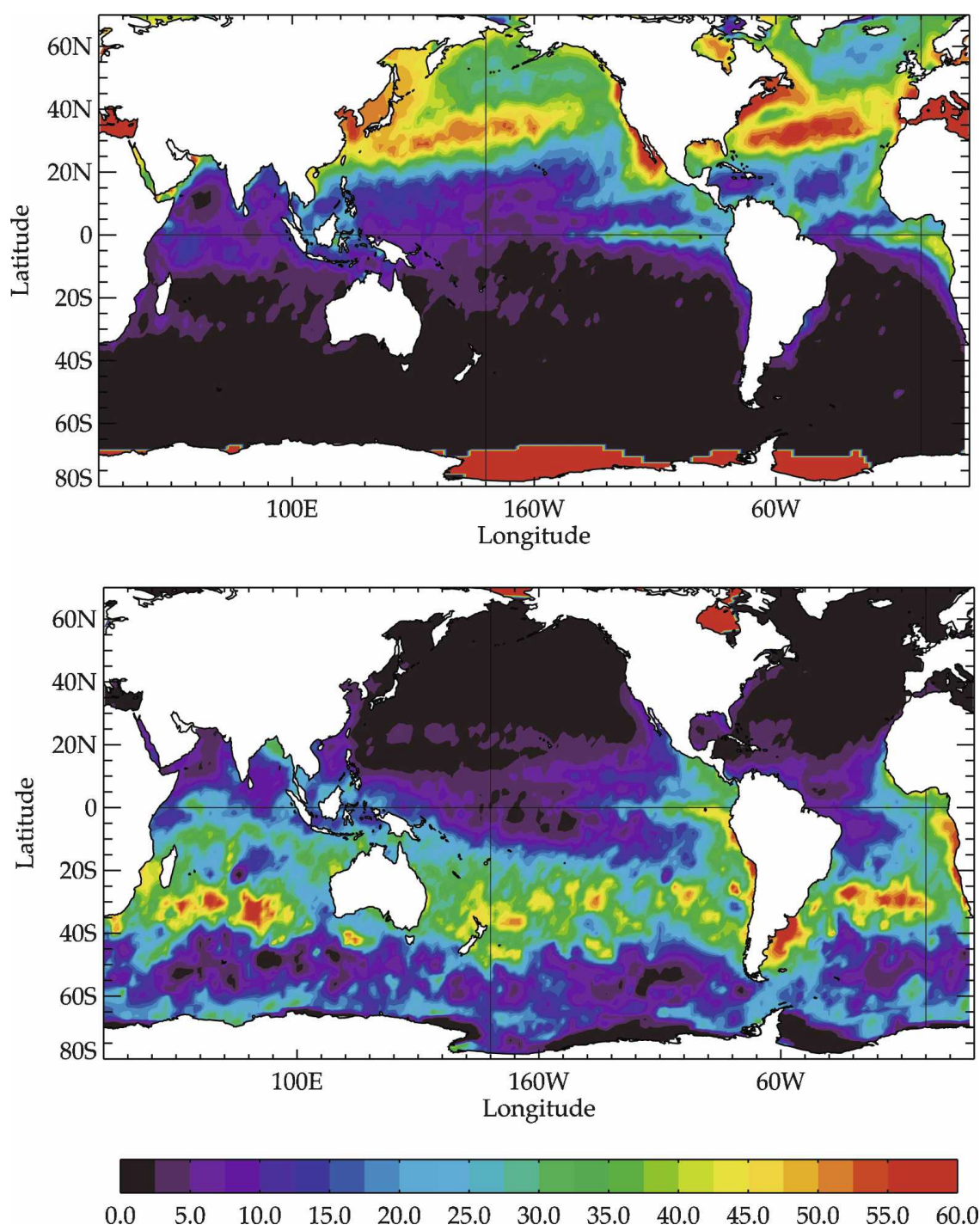

FIG. 2. Mean shortwave radiation $\left(\mathrm{W} \mathrm{m}^{-2}\right)$ at the base of the mixed layer in (top) July and (bottom) January. Solar irradiance at the surface is derived from the standard bulk formulas and climatological cloud cover used to force the model (see Iudicone et al. 2008). Solar irradiance is assumed to be attenuated as in the standard clear-water double-exponential formulation, with $e$-foldings of 0.35 and $23 \mathrm{~m}$ for the near-IR and visible wavelengths, respectively [the same formulation is used in the ice-ocean model; e.g., Manizza et al. (2005)]. A recent climatology is used for the estimate of the mixed layer depth (de Boyer Montegut et al. 2004). A significant warming of the base of the mixed layer is observed in the tropics in both seasons (see also Siegel et al. 1995), while extratropical regions are warmed only during summer (see also Ohlmann et al. 1996).

the solar penetrative shortwave flux is considered, with applications to the tropics; section 4 discusses the implications of using a neutral density framework, with applications to the Southern Ocean; and the last section contains the conclusions. Appendix A describes the assumptions in the computation of the neutral density evolution in terms of the temperature and salinity tendencies; appendix B presents the implementation and validation of the diagnostics in a global ice-ocean coupled model; and appendix $\mathrm{C}$ summarizes the model configuration.

\section{Theoretical developments}

Walin (1982) derived elegant relations between water-mass formation and diffusive and radiative (nonad- 
vective) heat fluxes, combining heat and volume budgets for an isothermal layer. This derivation has lately been repeated in terms of potential density (Tziperman 1986; Speer and Tziperman 1992; Marshall et al. 1999; Nurser et al. 1999; Viúdez 2000).

Here, we first establish the conservation equation of (neutral) density. Then we rederive the Walin formulation directly from the equation of conservation of (neutral) density (i.e., without using the volume budget).

\section{a. Density evolution equation in terms of potential temperature and salinity}

The conservation equation of a tracer, $\tau=\theta$ or $S$, can be expressed as

$$
\frac{D \tau}{D t}=d_{\tau}+f_{\tau}
$$

where $d_{\tau}$ is the tendency due to mixing processes and $f_{\tau}$ is the tendency due to external forcing.

The potential temperature and salinity forcing terms are given by

$$
\begin{aligned}
f_{\theta}= & \frac{Q-I_{0}}{\rho C_{p}} \delta_{z=0}+\frac{1}{\rho C_{p}} \nabla \cdot I+e\left(T_{e}-\mathrm{SST}\right) \delta_{z=0} \\
& +\frac{G}{\rho C_{p}} \delta_{z=-H} \\
f_{S}= & e S \delta_{z=0}
\end{aligned}
$$

where $Q$ is the net heat flux across the sea surface, $I_{0}$ is the total surface solar radiation (i.e., the portion of the surface heat flux that penetrates inside the ocean), $I=$ $I(\mathbf{x})$ is the solar irradiance flux that reaches the interior, SST is the sea surface temperature, $e$ is the net surface freshwater flux (evaporation minus precipitation and river runoffs), $T_{e}$ is the temperature of the surface freshwater budget (i.e., the temperature of the different freshwater sources), $G$ is the geothermal heat flux across the ocean sea floor $(z=-H)$, and $\delta$ is the Dirac operator (homogeneous to the inverse of a length).

The potential temperature and salinity mixing terms are given by

$$
\begin{aligned}
& d_{\theta}=\boldsymbol{\nabla} \cdot(\mathbf{k} \nabla \theta)+F S_{\theta}, \\
& d_{S}=\boldsymbol{\nabla} \cdot(\mathbf{k} \nabla S)+F S_{S},
\end{aligned}
$$

where $\mathbf{k}$ is the diffusive tensor and $F S_{\theta}$ and $F S_{S}$ represent sources and sinks due to double-diffusive convection of both the "diffusive" and salt fingering varieties.
The equation of evolution of the locally referenced potential density $\rho$, defined at a reference pressure chosen as the local pressure $p_{r}$, is

$$
\frac{1}{\rho} \frac{D \rho}{D t}=-\alpha\left(\theta, S, p_{r}\right) \frac{D \theta}{D t}+\beta\left(\theta, S, p_{r}\right) \frac{D S}{D t},
$$

where $\alpha$ is the thermal expansion coefficient and $\beta$ is the saline contraction coefficient for potential temperature, whose relationships with the standard coefficients $\alpha^{\prime}$ and $\beta^{\prime}$ for in situ temperature are (Gill 1982; McDougall 1987a)

$$
\alpha=\frac{\alpha^{\prime}}{(\partial \theta / \partial T)_{S, p}}, \quad \beta=\beta^{\prime}+\alpha(\partial \theta / \partial S)_{T, p} .
$$

Using (1), Eq. (3) can be expressed in terms of nonadvective processes and external forcing acting on $\theta$ and $S$ :

$$
\frac{D \rho}{D t}=\rho\left[-\alpha d_{\theta}+\beta d_{S}\right]+\rho\left[-\alpha f_{\theta}+\beta f_{S}\right],
$$

or more concisely

$$
\frac{D \rho}{D t}=\rho\left(d_{\rho}+f_{\rho}\right) .
$$

To relate the material derivative of locally referenced potential density in (5) to the corresponding changes of neutral density $\gamma$, we draw on the work of McDougall and Jackett (2005) who derive a comprehensive expression for the material derivative of neutral density, repeated here as (A1) in appendix A. This expression shows that, even in the absence of irreversible mixing processes, neutral density is not materially conserved. However, as discussed in appendix A, this lack of exact material conservation is usually not numerically significant compared with the effects of irreversible mixing (which cause the material derivatives of potential temperature and salinity, $D \theta / D t$ and $D S / D t$ ). From (A4) of appendix A, we then have

$$
\frac{1}{\gamma}\left(\frac{\partial \gamma}{\partial t}+\mathbf{U} \cdot \boldsymbol{\nabla} \gamma\right) \approx \frac{b}{\rho}\left(\frac{\partial \rho}{\partial t}+\mathbf{U} \cdot \boldsymbol{\nabla} \rho\right) .
$$

The factor $b$ is the ratio of the spatial gradients of neutral density and locally referenced potential density, $|\nabla \gamma| /|\nabla \rho|$, and is a nontrivial function of space: the $b$ depends on the thermodynamic properties of seawater and the water-mass distribution in the World Ocean, and often $b$ can be different from unity, as discussed in section 4. (In the following, the ratio $\gamma / \rho$ will be assumed to be equal to 1.) By multiplying (5) by $b$, we obtain the evolution equation for neutral density; 


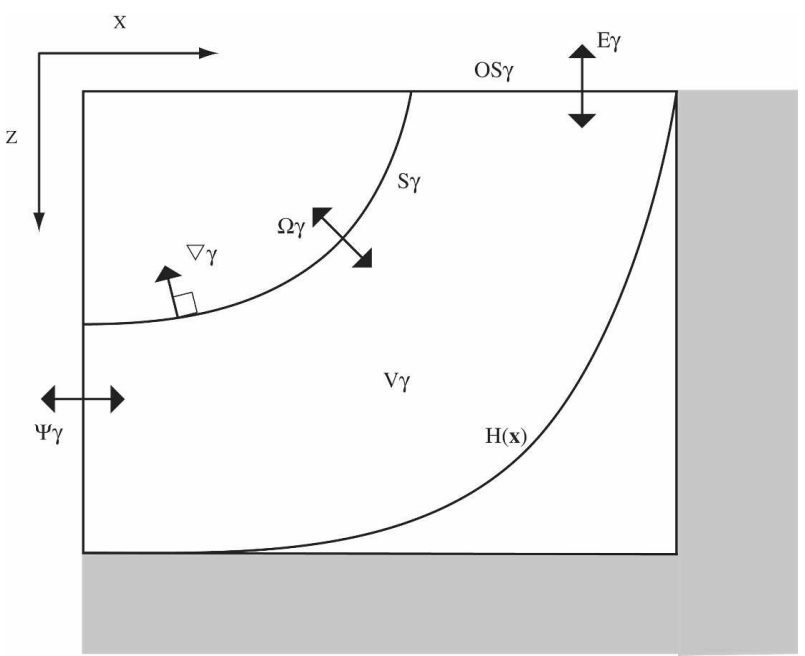

FIG. 3. Sketch of the ideal oceanic basin discussed in section 2 .

that is, we obtain the evolution of a global variable instead of that of a local one:

$$
\frac{D \gamma}{D t}=\frac{\partial \gamma}{\partial t}+\mathbf{U} \cdot \nabla \gamma=\gamma b\left(d_{\rho}+f_{\rho}\right)=\gamma\left(d_{\gamma}+f_{\gamma}\right) .
$$

\section{b. Water-mass formation and transformation}

Let us consider a limited area of the ocean with an open boundary (Fig. 3). We denote $S_{\gamma}$ as the surface with neutral density $\gamma$ over the limited domain; $V_{\gamma}$ the volume sandwiched between two surfaces $S_{\gamma}$; the ocean bottom $H$; the ocean surface $\mathrm{OS}_{\gamma} ; \psi_{\gamma}$ and $E_{\gamma}$ the volume fluxes of fluid entering/exiting the domain $V_{\gamma}$ across the open boundary and surface, respectively; and $\Omega_{\gamma}$ the total volume flux across the $S_{\gamma}$ (i.e., the dianeutral volume flux). The sign convention is that all the fluxes are positive if entering $V_{\gamma}$.

We introduce two scalar quantities, $\omega_{\gamma}$ and $\nabla_{\perp} \gamma$, defined as the velocity across the moving $S_{\gamma}$ and the gradient of $\gamma$ in the direction normal to $S_{\gamma}$. In this framework, the material derivative of $\gamma$,

$$
\frac{\partial \gamma}{\partial t}+\mathbf{U} \cdot \nabla \gamma
$$

reduces to the product $\omega_{\gamma} \nabla_{\perp} \gamma$ so that, from (7) $\omega_{\gamma}$, can be expressed as

$$
\omega_{\gamma}=\gamma\left(d_{\gamma}+f_{\gamma}\right)\left(\nabla_{\perp} \gamma\right)^{-1} .
$$

The total volume flux $\Omega_{\gamma}$ across $S_{\gamma}$ is thus the summation of the flux $\omega_{\gamma} d s$ over $S_{\gamma}: \Omega_{\gamma}=\iint S_{\gamma} \gamma\left(d_{\gamma}+f_{\gamma}\right)$ $\left(\nabla_{\perp} \gamma\right)^{-1} d s$

Making use of a generalized form of the Leibnitz theorem, the right-hand term can be transformed as

$$
\begin{aligned}
\Omega_{\gamma} & =\frac{\partial}{\partial \gamma} \iint_{V_{\gamma}} \gamma b\left(d_{\rho}+f_{\rho}\right) d v \\
& =\frac{\partial}{\partial \gamma} \int \underbrace{\iint_{V_{\gamma}} \int_{D} \gamma b d_{\rho} d v}_{D}+\frac{\partial}{\partial \gamma} \underbrace{\iint_{V_{\gamma}} \int b f_{\rho} d v}_{F},
\end{aligned}
$$

or more concisely

$$
\Omega_{\gamma}=\frac{\partial D}{\partial \gamma}+\frac{\partial F}{\partial \gamma},
$$

where we have introduced $D$ and $F$, the volume-integrated effect of mixing and forcing over $V_{\gamma}$. Here $\Omega_{\gamma}$ is usually referred to as the water-mass transformation from water masses lighter than $\gamma$ into water masses denser than $\gamma$, while $M_{\gamma}=\partial \Omega_{\gamma} / \partial \gamma$, the convergence of $\Omega_{\gamma}$, is referred to as the water-mass formation at a given density $\gamma$ (Walin 1982; Speer and Tziperman 1992). Therefore, $\partial D / \partial \gamma$ and $\partial F / \partial \gamma$ are the transformations driven by ocean physics and external forcing, respectively. Finally, we note that, setting $b=1$ and substituting $\gamma$ by $\rho$ in (7) to (10), we obtain a potential density formulation of water-mass formation/transformation.

Equation (10) expresses the fact that a cross-dianeutral volume flux (transformation) directed from light to dense, $\Omega_{\gamma}>0$, requires a density supply either by ocean physics or by the forcing. This expression abridges the works of Nurser et al. (1999) and Marshall et al. (1999) with the addition that here we are in the neutral density framework and that (10) does not represent the diapycnal density flux across the extended isopycnal made up of the isopycnal and its surface extension, but rather it is the volume-integrated effect of the right-hand side of (3). This has several important consequences that will be discussed in sections 3 and 4 . The implementation of (10) for application to oceanographic databases (in situ data, model outputs) is presented in appendix B.

Up to now we have not assumed either incompressibility or stationarity. Assuming incompressibility and considering the volume budget of $V_{\gamma}$, we have the equation for the water-mass evolution in a neutral density framework:

$$
\frac{\partial V_{\gamma}}{\partial t}-\Psi_{\gamma}-E_{\gamma}=\Omega_{\gamma}
$$

\section{Surface fluxes}

Using (2a) the forcing term $\partial F / \partial \gamma$ in Eq. (10) can be written from 


$$
\begin{aligned}
F= & \iint_{O S_{\gamma}}-b \alpha \frac{Q-I_{0}}{C_{p}} d s+\iint_{O S_{\gamma}} b \gamma e\left[-\alpha\left(T_{e}-\mathrm{SST}\right)\right. \\
& +\beta S] d s+\iint_{z=-H}-b \alpha \frac{G}{C_{p}} d s+\iiint_{V_{\gamma}}-b \alpha \frac{1}{C_{p}} \nabla \cdot I d v .
\end{aligned}
$$

The key point here is that the forcing term does not reduce to a surface integral as in the classical theory but the last term takes into account the three-dimensional nature of the forcing.

\section{a. Relation with previous theories}

The classical formulation for the water-mass transformations associated with external forcings (e.g., Tziperman 1986; Speer and Tziperman 1992) can be written, using a formalism consistent with section 2 , as $\partial F / \partial \rho$, where

$$
F=\iint_{\mathrm{OS}_{\rho}}\left(-\alpha \frac{Q}{C_{p}}+\rho \beta S e\right) d s .
$$

In practice, it corresponds to integrating the surface buoyancy flux at the outcrop.

There are several differences between (12) and (13). The first is that (12) assumes a neutral density framework, while the diagnostic (12) is usually applied in a potential density framework, as discussed in section 4 . Here, setting $b=1$ and substituting $\gamma$ by $\rho$ in (7) to (10) and using $\alpha=\alpha(\theta, S, 0), \beta=\beta(\theta, S, 0)$, a potential density formulation for external forcings of water-mass formation/transformation can be derived.

Second, in (12) the surface volume flux plays a role only as driver of a heat flux, via the temperature difference $T_{e}-$ SST. Suppose an ocean without salt and forced only by precipitation, the temperature of which is equal to the SST. In this case, (12) gives $F=0$; that is, there will be no transformation of water masses. On the other hand, $F \neq 0$ in (13) because of the last term in the parentheses. This term only adds extra volume in each density class, just as $\Psi_{\gamma}$ does, and for this reason we moved the corresponding term in the neutral density framework to the left-hand side of (11) (see also Large and Nurser 2001).

Third, (12) takes into account the geothermal heating [third term in (12)] that represents a significant forcing for the lower limb of the thermohaline circulation (e.g., Scott et al. 2001; Dutay et al. 2003; Adkins et al. 2005).

Finally, the last term in (12), associated with the penetrative solar irradiance $I$, is omitted in (13), where all

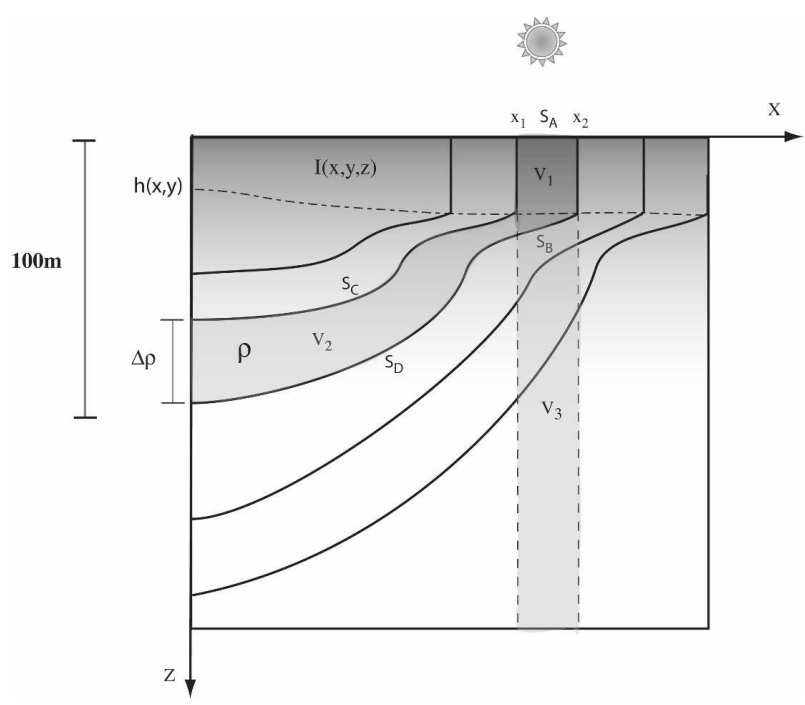

FIG. 4. Sketch of the upper ocean stratification in the presence of a shallow mixed layer (see text).

the heat exchanged with the atmosphere is supposed to be captured at the surface, that is, in the ocean mixed layer. Thus, there is in (13) the implicit assumption that internal sources of buoyancy are neglected (e.g., Marshall et al. 1999; Donners et al. 2005).

Let us consider this point in more detail. First, we note that solar energy, the main term in the heat flux in most oceans and seasons, is penetrative. It is most accurately characterized as a function of wavelength (e.g., Mobley 1994; Ohlmann et al. 1996). In open ocean waters, the net spectral irradiance flux for a given wavelength $E(\mathbf{x}, \lambda)$ is given by the Beer-Lambert relation:

$$
E(\mathbf{x}, \lambda)=E_{0}(\mathbf{x}, \lambda) e^{\left[-K_{w}(\mathbf{x}, \lambda)-K_{\mathrm{chl}}(\mathbf{x}, \lambda)\right] z},
$$

in which $K_{w}(\mathbf{x}, \lambda)$ and $K_{\mathrm{chl}}(\mathbf{x}, \lambda)$ are the spectral diffuse attenuation coefficients due to pure water and chlorophyll-related materials, respectively. The inverse of the attenuation coefficients, or penetration depth, varies with wavelength from a few microns to a few tens of meters. The net irradiance flux $I(\mathbf{x})=\int \lambda_{\text {sol }} E(\mathbf{x}, \lambda) d \lambda$, integrated over the solar spectrum, thus heats roughly the first $100 \mathrm{~m}$ of the ocean and in several cases reaches the (highly) stratified layer below the mixed layer (e.g., Siegel et al. 1995; Ohlmann et al. 1996). As a consequence, part of the solar flux entering at a given location warms waters at much higher densities than the surface density. Finally, the total solar irradiance is often parameterized as a sum of exponentials (e.g., Ohlmann and Siegel 2000).

Next, consider the case of the summer upper stratification of an ideal ocean basin (a vertical slice of an infinite ocean; Fig. 4) in which a well-developed sea- 
sonal pycnocline is present; that is, subsurface densities are much higher than the surface density. The oceanic region is here partitioned into finite volume isopycnal or neutral layers of thickness $\Delta \rho$ (here we do not distinguish between locally referenced potential density and neutral density) and we will focus on the isopycnal layer $\rho$ of volume $V\left(V=V_{1}+V_{2}\right)$, outcropping in the region $x_{1}<x \leq x_{2}$.

First, we note that the solar radiative forcing acting on the whole water column identified by $x_{1}<x \leq x_{2}$ is

$$
F_{\rho A}=\iint_{\left(\mathbf{x}: x_{1}<x \leq x_{2}\right)} \frac{\nabla \cdot I}{\rho C_{p}} d v=\iint_{\left(\mathbf{x}: x_{1}<x \leq x_{2}, z=0\right)} \frac{I(\mathbf{x})}{\rho C_{p}} d s-\underbrace{}_{\sim 0} \int_{\left(\mathbf{x}: x_{1}<x \leq x_{2}, z=-H\right)} \frac{I(\mathbf{x})}{\rho C_{p}} d s \approx \iint_{\left(\mathbf{x}: x_{1}<x \leq x_{2}, z=0\right)} \frac{I(\mathbf{x})}{\rho C_{p}} d s,
$$

since the irradiance at the bottom is attenuated to zero in open ocean waters, where $H \gg 100 \mathrm{~m}$. Taking the limit,

$$
\lim _{\Delta \rho \rightarrow 0} \frac{1}{\Delta \rho} F_{\rho A},
$$

the standard treatment for solar flux forcing in (13) is recovered (e.g., Speer and Tziperman 1992; Nurser et al. 1999), and (13) thus presumes that 1) the whole solar energy entering at the outcrop of the layer $\rho$ is associated with the volume entire $V$ of the same layer $\rho$ and 2) the warming of the layer is limited to its subsurface region (i.e., the mixed layer).

Actually, the shortwave radiative forcing acting on the layer $\rho$ with volume $V_{A}$ is

$$
\begin{aligned}
& R_{\rho}=\iiint_{V} \frac{\boldsymbol{\nabla} \cdot I}{\rho C_{p}} d v=\iiint_{V_{1}} \frac{\boldsymbol{\nabla} \cdot I}{\rho C_{p}} d v+\iiint_{V_{2}} \frac{\boldsymbol{\nabla} \cdot I}{\rho C_{p}} d v=
\end{aligned}
$$

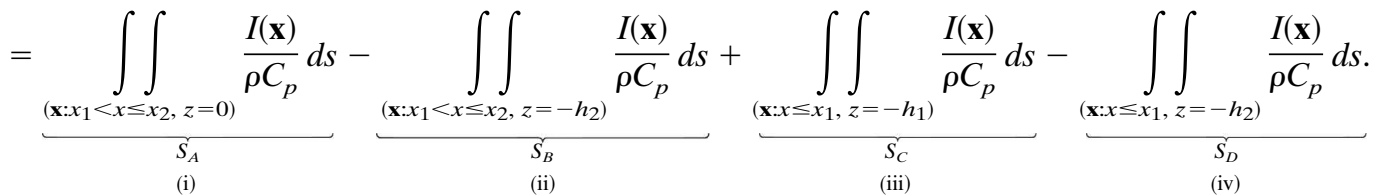

The terms above can be interpreted as (i) the total irradiance entering at the outcrop; (ii) the irradiance exiting the isopycnal layer and warming the deeper layers $\left(V_{3}\right)$ in the outcrop region of $\rho$; (iii) the irradiance entering the layer $\rho$ in the stratified region outside the outcrop; and finally (iv) the irradiance leaving the layer in the latter region. The contribution to the water-mass transformation by shortwave radiation in (12) is obtained taking the limit $F R_{\rho}=\lim _{\Delta \rho \rightarrow 0}(1 / \Delta \rho) R_{\rho}$.

In the equation for $R_{\rho}$ above the term (i) is, in fact, equal to $F_{R}$ derived from (14) above. The classical formulation thus assumes that the other three terms, related to the solar energy penetrating the thermocline, are negligible. In other words, in a highly stratified ocean the solar warming in the outcrop region could be overestimated using the classical treatment by an amount given by (ii), while the warming of adjacent deeper (denser) isopycnals could be, in principle, underestimated by an amount given by (iii) minus (iv). As a result, in warm seasons (13) leads to overestimation of the warming at the lowest outcropping densities and an underestimation of the warming of intermediate (subsurface) layers.

Moreover, below the thin mixed layers, which are typical of upwelling regions of the tropics or of some highly stratified marginal seas, such as the Mediterranean Sea (e.g., de Boyer Montegut et al. 2004; D'Ortenzio et al. 2005), part of the solar energy can reach the permanent pycnocline. The oceanic region directly affected by the air-sea interaction can thus be thicker than the maximum mixed layer depth over the year, usually assumed as the boundary with the interior (e.g., Marshall et al. 1999).

Finally, when the assumption of steady state applies, mixing can be estimated using volume conservation, that is, as the residual between the water mass formation via surface forcing and the net flux exiting the domain, as can be the case in inversion of in situ data. A likely consequence of the use of (13) is thus an overestimation of the diapycnal mixing acting on the isopycnal layer, as discussed in the following. 


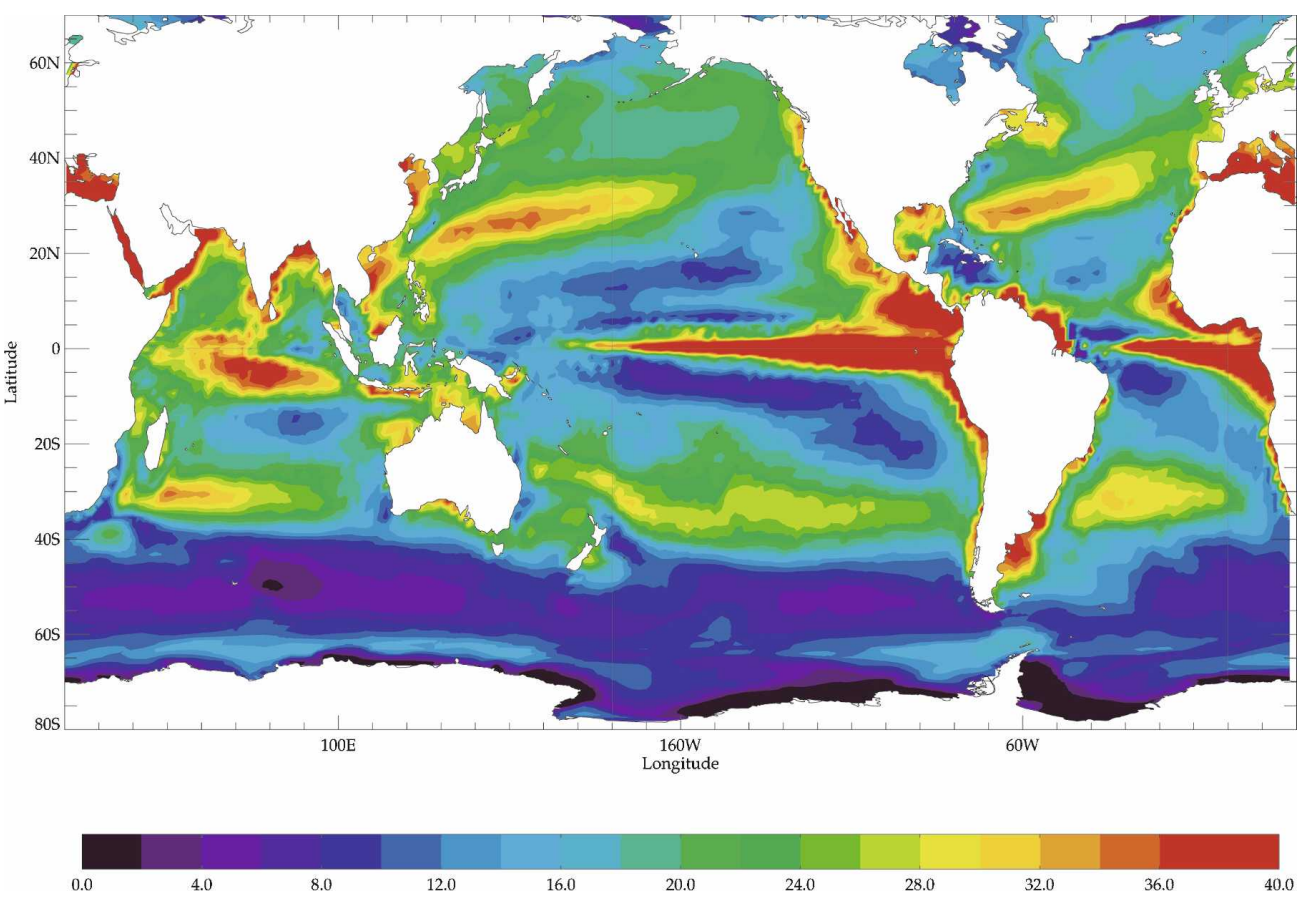

FIG. 5. Heat flux crossing the base of the climatological mixed layer in the model [annual mean values $\left.\left(\mathrm{W} \mathrm{m}^{-2}\right)\right]$. The mixed layer in the model is defined using a threshold criterion on density $\left(\Delta \sigma_{0}=0.01\right)$.

\section{b. The impact of the penetrative character of the solar irradiance}

The impact of the inclusion of the penetrative character of the surface forcing on the estimate of surface forcing and mixing has been estimated via the analysis of the outputs of a global ice-ocean model (see appendix C). The amount of solar irradiance reaching the base of the mixed layer is indeed significant almost everywhere (Fig. 5). It has its maximum in the equatorial upwelling regions. The subtropical gyres are also affected as well as the upwelling regions at the eastern boundaries. As expected, the deep heating is less important in the Southern Ocean and, in particular, along the path of the Antarctic Circumpolar Current, where the winds are strong and thick mixed layers are always present. The "Antarctic Divergence" also receives a significant amount of heat.

More quantitatively, the global transformations due to surface forcings have been computed with both the classical and the new approach and are presented in Fig. 6. (Note that in this global estimate, Northern Hemisphere and Southern Hemisphere formations sometimes cancel out.) To ease the comparison with previous studies, here we use a straightforward variation of (12) that makes use of potential density for the computation of water-mass formation and of $\sigma_{0}$ for the water-mass classification, as discussed in section $2 \mathrm{~b}$. Us- ing the classical approach [Eq. (13), Fig. 6a], we obtain a general picture of the transformations, which presents a maximal transformation of $90 \mathrm{~Sv}\left(\mathrm{~Sv} \equiv 10^{6} \mathrm{~m}^{3} \mathrm{~s}^{-1}\right)$ at $21.5 \sigma_{0}$ (tropical waters), due to warming and freshening, while cooling promotes the formation of about 40 Sv subpolar mode and intermediate water (IW) and of about $15 \mathrm{~Sv}$ of deep, bottom, and marginal seas waters. Freshening participates in forming the Subantarctic Mode Waters (SAMW) and Antarctic Intermediate Waters (AAIW) in the Southern Ocean. The global pattern is in general agreement with a previous estimate by Speer et al. (1995) that used climatologies of in situ data and of surface forcings (their Fig. 3a: They did not include data from the region south of $30^{\circ} \mathrm{S}$ and thus missed the water-mass formation in the Southern Ocean). The global transformations evaluated using (12) (Fig. 6b) demonstrate that, using the previous approach, the formation of both light and mode waters (MWs) is overestimated by several tens of Sverdrups (warming is overestimated for light waters while it is underestimated for the densities of the layers underneath, as discussed in section 3a) and the mismatch amounts to a factor of $\sim 2$. The disagreement remains significant for intermediate water formation, while it has no impact on the densest water masses. Interestingly, we found that the formation of the lightest water masses is basically due to freshening. In fact, it is asso- 

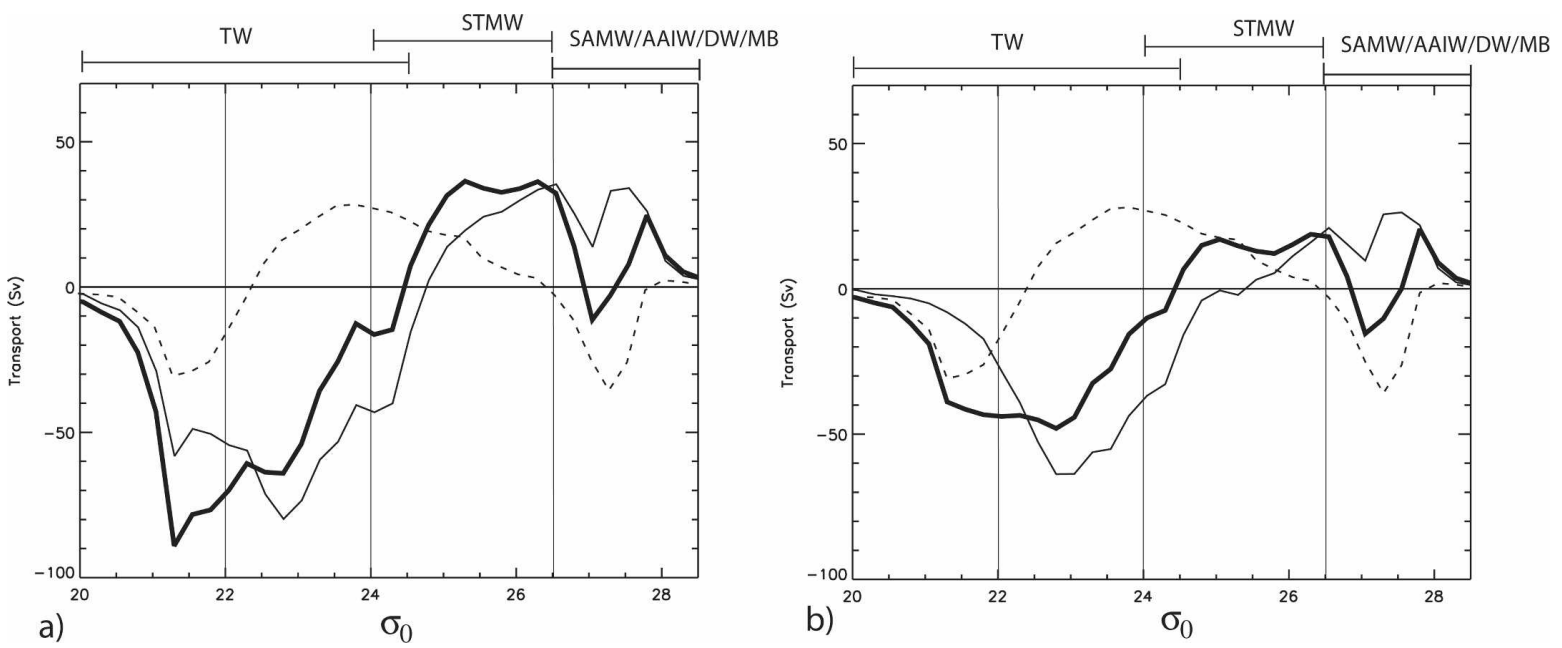

FIG. 6. Global annual transformations due to surface air-sea and ice-ocean fluxes computed via (a) (13) and (b) (12). The thick line represents the total annual transformations; the thin continuous line is the heat contribution; and the dashed line the freshwater contribution. The main density range of the water masses has also been reported (TW: tropical waters; STMW: Subtropical Mode Water; DW: deep and bottom waters; MB: waters in marginal basins such as the Mediterranean Sea.) The vertical lines have been added to facilitate comparison.

ciated with the formation of barrier layers in the tropics (e.g., de Boyer Montegut et al. 2004).

Most of the transformation on a global scale occurs in the tropics, which is characterized by large positive heat fluxes via shortwave radiation and by the presence of large regions of upwelling (e.g., Schott et al. 2004) in which a large upward vertical advection creates relatively shallow mixed layers (e.g., de Boyer Montegut et al. 2004). A first glance of the impact of the penetration of surface heating below and at the base of the mixed layer can be obtained from Fig. 7 in which the diapycnal fluxes across the 25.5 isopycnal (in the range of the subtropical cells) are presented. The vertical mixing (which is the main mixing mechanism) lightens the water masses almost everywhere in the tropical areas; it is especially large in the eastern equatorial upwellings and significant in the whole tropical region. A net solarinduced upwelling is also noticeable in the eastern regions of the tropics, a flux that is clearly smaller than the diffusive flux but absolutely not negligible.

We focus here on the radiative heat flux in the tropical Pacific Ocean, which represents the region of the largest warm water formation on a global scale, and more specifically on the region bounded by $40^{\circ} \mathrm{S}-40^{\circ} \mathrm{N}$, $170^{\circ} \mathrm{W}$ and the west coast of the Americas (see Fig. 7). This region includes most of the Pacific Subtropical Mode Water (STMW) formation regions (Hanawa and Talley 2001), waters that are implicated in the subtropical cell circulation (Schott et al. 2004). First, we note that the pattern of the diffusive fluxes across $25.5 \mathrm{~kg}$ $\mathrm{m}^{-3}$ roughly describes the regions of upwelling (nega- tive values) and downwelling (positive values) (see Plate 2 in Schott et al. 2004). They present a maximum at the base of the mixed layer in the cold tongue at the equator. The upward diffusive transport is significant also in the regions of the equatorial countercurrents, specifically along $4^{\circ} \mathrm{S}$ and $4^{\circ} \mathrm{N}$ in the central and western part of the basin, and in the region immediately southeastward of Central America. The solar irradiance warms the subsurface waters in the cold tongue and in the adjacent regions.

In general and more quantitatively, the region is characterized by a large warming for almost all of the density range (Fig. 8a), while freshening forms the lightest tropical waters and evaporation opposes the warming in the range between 22.5 and $25.5 \sigma_{0}$. The net result is the production of about $40 \mathrm{~Sv}$ of water lighter than $23.0 \sigma_{0}$. Considering the ensemble of the transformation processes, we observe that this large positive buoyancy flux for the tropical waters is partly opposed by mixing (Fig. $8 \mathrm{~b}$ ). At larger densities $\left(>24.5 \sigma_{0}\right)$, less exposed to surface fluxes, mixing instead promotes the transformations of dense STMW and deeper waters (mostly SAMW) into dense STMW that lighten further because of the surface warming. The net result is the formation of about $15 \mathrm{~Sv}$ of light water $\left(<23 \sigma_{0}\right)$ at the expense of water denser than $25.5 \sigma_{0}$ (STMW and SAMW, essentially). The impact of the solar penetrative heating on the transformations can be appreciated in Fig. 8c, in which the total transformation due to surface forcings is compared with the same estimate computed using (13). The former formulation produces an 

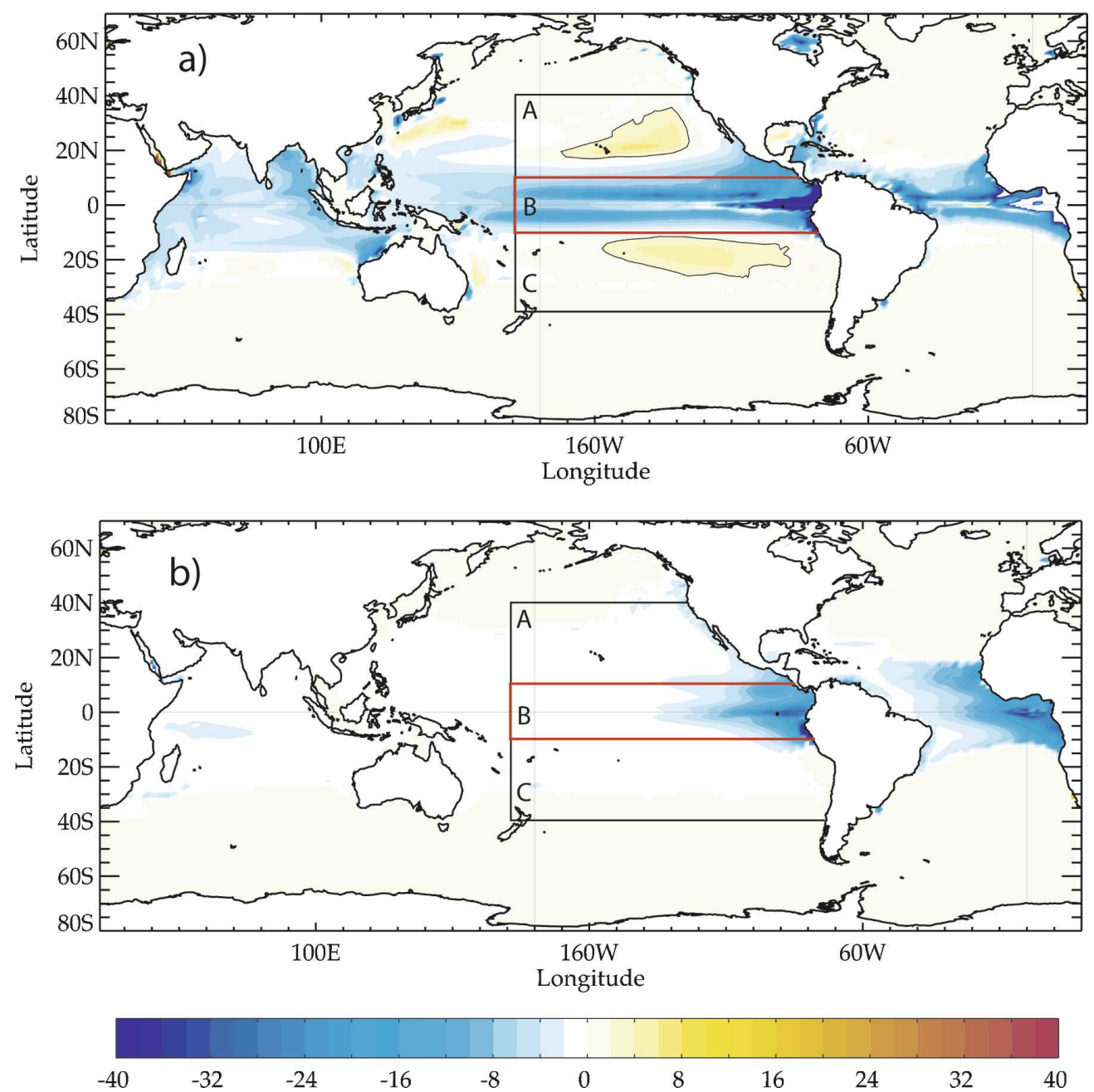

FIG. 7. Dianeutral velocities in the interior on a particular isopycnal computed by applying (10) at each model water column. (a) Dianeutral velocity across the isopycnal $25.5 \sigma_{0}$ due to the vertical mixing term. [This equivalent diapycnal velocity has been computed dividing the transport from (10) by the area of the grid box.] Positive (negative) values represent transport toward higher (lower) densities. (b) Dianeutral velocity across the isopycnal $25.5 \sigma_{0}$ due to the solar flux. Positive (negative) values represent a net transport toward higher (lower) densities. In all the cases a linear interpolation has been used in the vertical to reduce the noise in the estimate. The Pacific box discussed in the text is also superimposed (the equatorial box is in red).

overestimation of the warming for the water lighter than $24.5 \sigma_{0}$ and an apparent cooling at greater densities, a cooling due to the missing solar heating input below the mixed layer that is somehow expected because the region includes the extratropics. Thus, by including the solar heating we obtain a considerably different view of the net annual budget of the forcing on the Pacific water-mass transformations.

The role of the equatorial upwelling, that is, the transformations occurring in the equatorial box $\mathrm{B}$ in Fig. 8d, is also examined. This box has fixed meridional boundaries at $10^{\circ} \mathrm{S}$ and $10^{\circ} \mathrm{N}$ so as to avoid the tropical cells and to seize the midpoint of the subtropical cells
(Hazeleger et al. 2001; Schott et al. 2004). The forcing (Fig. 8d) presents a large warming centered at about $23.0 \sigma_{0}$ and extending to $26.0 \sigma_{0}$. The freshwater input forms the lightest waters, as in the global analysis above. By comparing Figs. $8 \mathrm{~b}$ and $8 \mathrm{~d}$, it can easily be spotted that most of the upwelling of dense waters in the region discussed here occurs in the equatorial area (see Fig. 8d). The estimate of the net STMW upwelling is coherent but somehow smaller than in experimental estimates [Schott et al. (2004); e.g., Sloyan et al. (2003), using an inverse model, gives $24 \pm 4 \mathrm{~Sv}$ across the $23.0 \sigma_{0}$ between $2^{\circ} \mathrm{S}$ and $2^{\circ} \mathrm{N}$ in the central Pacific], while here we found an upwelling of $\sim 5 \mathrm{~Sv}$ of water 

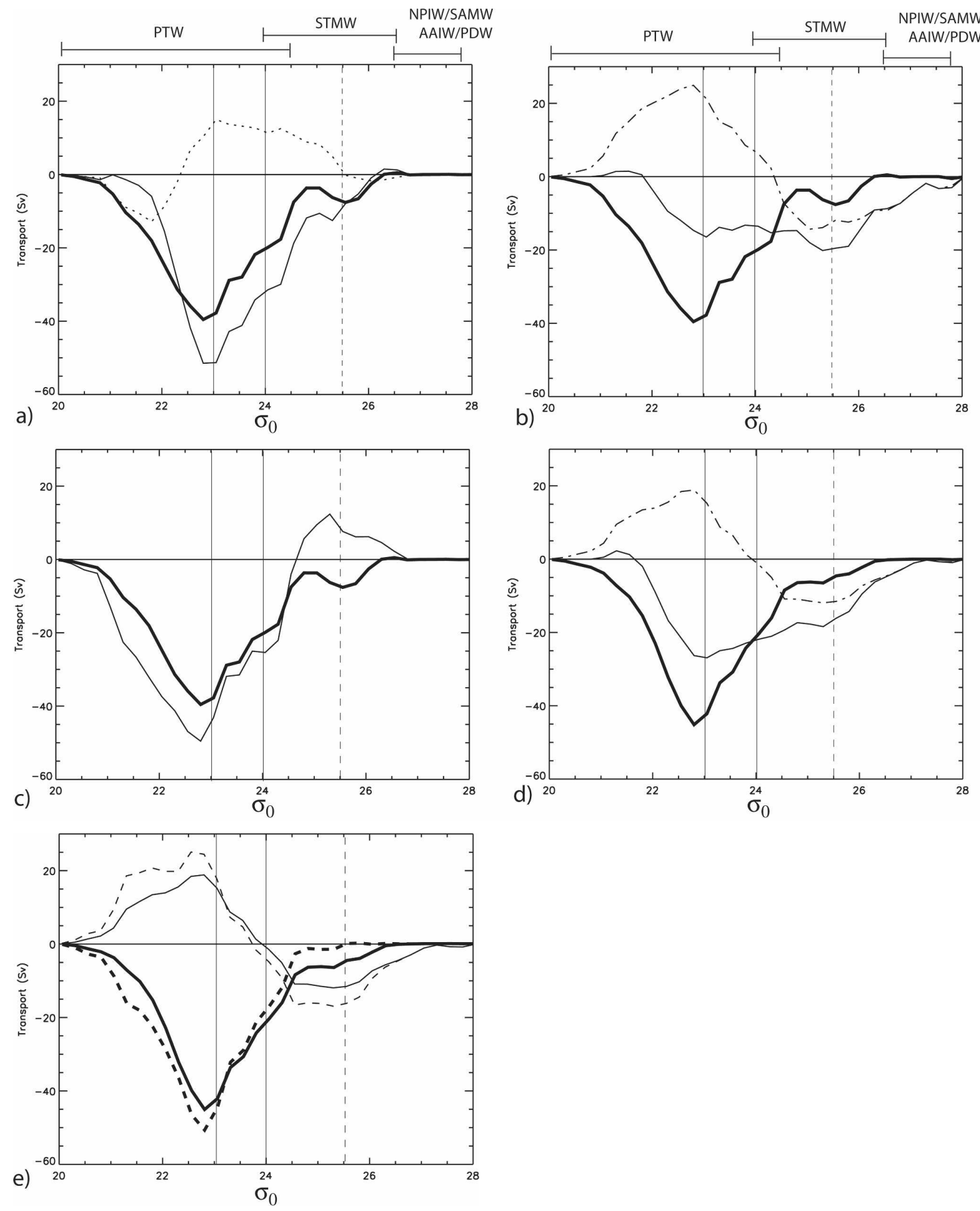

FIG. 8. (a) Water mass transformation due to surface forcings in the Pacific $\left(40^{\circ} \mathrm{S}-40^{\circ} \mathrm{N} ; 170^{\circ} \mathrm{W}-\right.$ American coast; Fig. 7$)$. The thick line represents the total annual transformations; the thin continuous line is the heat contribution; and the dashed line the freshwater contribution. (b) Total water-mass transformation in the Pacific box $(\mathrm{A}+\mathrm{B}+\mathrm{C})$. The thick line represents the surface buoyancy fluxes; the dashed line is the mixing, essentially the vertical component; and the thin line represents the net water-mass transformations $\Omega_{\sigma}$. (c) Transformations due to surface buoyancy fluxes. The thick line is computed using (12), while for the thin line the classical approach has been used. (d) As in (b) but for the equatorial box (B). (e) Thick continuous line: water-mass transformation in the equatorial box (B) due to surface forcings computed using (12). Thick dashed line: water-mass transformation in the equatorial box (B) due to surface forcings computed using (13). Thick continuous line: water-mass transformation in the equatorial box (B) due to mixing computed as a residual of surface forcing transformations computed via (12) and transports at $30^{\circ} \mathrm{S}$ (sum of advective contributions). Thin continuous line: water-mass transformation in the equatorial box (B) due to mixing computed as a residual of surface forcing transformations computed via (13) and transports at $30^{\circ} \mathrm{S}$ (sum of advective contributions). Superimposed are the main Pacific water masses as defined in Fine et al. (2001; PTW: Pacific tropical waters; NPIW: North Pacific Intermediate Water; PDW: Pacific Deep Water). The continuous vertical lines mark the cores of the subtropical cells (see text). The dashed vertical line marks the density layer discussed in Fig. 7. 
denser than 26.3-26.5 $\sigma_{0}$, which is the densest upwelling layer in the experimental estimates (Sloyan et al. 2003; Schott et al. 2004). Interestingly, the net water-mass formation in the region ( $\sim 25 \mathrm{~Sv}$ across $\left.23.0 \sigma_{0}\right)$ is larger than in the case of the entire domain (Fig. 8b). The residual is mostly due to the thermodynamic processes associated with the subtropical cells (the formation in A and $\mathrm{C}$ and destruction in $\mathrm{B}$ of the STMW) that adds $\sim 7$ $\mathrm{Sv}$ across $23.0 \sigma_{0}$ at north and $\sim 6 \mathrm{~Sv}$ across $24.0 \sigma_{0}$ at south (not shown).

The classical approach (Fig. 8e) gives for the equatorial region a reduced warming at STMW densities and, again, an overestimation of the warming for the lightest water masses (barrier layers). Interestingly, this latter estimate quite closely resembles the only available previous estimate, reported in Large and Nurser (2001), of transformations occurring in the Pacific between $10^{\circ} \mathrm{S}$ and $10^{\circ} \mathrm{N}$ (including also the warm pool west of $170^{\circ} \mathrm{W}$ : here not included). Using in situ data and forcing climatologies, they show that a large warming characterizes the lightest tropical waters and that there is no warming for densities larger than $25.0 \sigma_{0}$. By considering Figs. 8e and 6 (which included the warm pool) we conclude that the rationale in discussing estimates of Speer et al. (1995) also applies here.

Finally, estimating the mixing as the residual between the surface forcing and the net formation rates measured at boundary sections [as in inverse model estimates, e.g., Sloyan et al. (2003)], we observe that the classical approach overestimates the diffusive upwelling of STMW across the $24.5 \sigma_{0}$ by $\sim 6 \mathrm{~Sv}$ (see Fig. $8 \mathrm{e}$ ).

\section{The neutral density framework}

\section{a. Isoneutral versus isopycnal approaches}

There are several advantages in using a neutral framework in the diagnosis of the water- mass transformation/formation. First, as discussed by McDougall (1984) and illustrated in Fig. 1, the isopycnal framework does not allow considering surface and interior transformation processes at the same time. More specifi- cally, most previous studies on water- mass transformations used potential density as the density variable, which presents well-known problems in identifying water masses below $500 \mathrm{~m}$, and locally it is not tangent to the neutral surface at depth. More importantly, $\partial D / \partial \gamma$ instead includes all the effects of ocean physics that appear in (3). In fact, $d_{\gamma}$ can be written as

$d_{\gamma} \equiv \boldsymbol{\nabla} \cdot[k \boldsymbol{\nabla} \gamma]+F S_{\gamma}=\boldsymbol{\nabla} \cdot\left[k_{I} \boldsymbol{\nabla}_{I} \gamma\right]+\boldsymbol{\nabla}\left[k_{\perp} \boldsymbol{\nabla}_{\perp} \gamma\right]+F S_{\gamma} ;$ that is, the tendency due to mixing processes can be expressed here in terms of the divergence of isoneutral and dianeutral fluxes (subscript $I$ and $\perp$, respectively) plus the sources and sinks due to double-diffusive processes such as salt fingering and diffusive convection. The first term on the right-hand side, in particular, includes the thermobaricity and cabbeling transport through $S_{\gamma}$ (McDougall 1987b). Indeed, even if $d_{\theta}$ and $d_{S}$ are expressed in flux form, $D$ cannot be transformed into fluxes across the boundary of $V_{\gamma}$ in the potential density framework. In other words, the nonlinear terms in the equation of state (expressed here through $\alpha$ and $\beta$ being functions of $\theta, S$, and pressure) are able to change the density of water masses in $V_{\gamma}$ and thus $\Omega_{\gamma}$, the water-mass transformation.

To better illustrate this point, we evaluate explicitly the transport across a neutral surface given by (10) in the ocean interior, that is, far away from the boundaries (thus $f_{\rho}=0$ ) and where we can assume $\nabla_{\perp} \sim \partial / \partial z$. Consequently, $D \gamma / D t \equiv \omega_{\gamma} \nabla_{\perp} \gamma \approx \omega_{\gamma} \partial \gamma / \partial z$ and $b=|\nabla \gamma| /$ $|\nabla \rho| \sim|\partial \gamma / \partial z| /|\partial \rho / \partial z|$, and thus

$$
\begin{aligned}
& \omega_{\gamma}=\gamma b d_{\rho}\left(\frac{\partial \gamma}{\partial z}\right)^{-1} \approx \gamma d_{\rho}\left(\frac{\partial \rho}{\partial z}\right)^{-1} \\
& \Omega_{\gamma} \approx \iint_{S_{\gamma}} \omega_{\gamma} d s=\iint_{S_{\gamma}} \gamma d_{\rho}\left(\frac{\partial \rho}{\partial z}\right)^{-1} d s .
\end{aligned}
$$

From (16) it can be easily seen that 1) $\omega_{\gamma}$ corresponds to the dianeutral velocity $e$ in McDougall (1987b) and thus 2) $\Omega_{\gamma}$, as defined in (10), contains all the known physics of the ocean interior. In particular, in this case $d_{\rho}$ is given by

$$
\begin{aligned}
d_{\rho} & =-\alpha d_{\theta}+\beta d_{S}=-\alpha\left[\nabla_{I} \cdot\left(k_{I} \nabla_{I} \theta\right)+\partial_{z}\left(k_{z} \frac{\partial \theta}{\partial z}\right)+F S_{\theta}\right]+\beta\left[\nabla_{I} \cdot\left(k_{I} \nabla_{I} S\right)+\partial_{z}\left(k_{z} \frac{\partial S}{\partial z}\right)+F S_{S}\right], \\
& =k_{I}\left(-\alpha \nabla_{I}^{2} \theta+\beta \nabla_{I}^{2} S\right)-\alpha \partial_{z}\left(k_{z} \frac{\partial \theta}{\partial z}\right)+\beta \partial_{z}\left(k_{z} \frac{\partial S}{\partial z}\right)-\alpha F S_{\theta}+\beta F S_{S},
\end{aligned}
$$

where the relation $\alpha \nabla_{I} \theta=\beta \nabla_{I} S$ has been used to simplify the result. The first term on the right, related to the nonlinearity of the equation of state, can be rewritten as (McDougall 1984) 


$$
\begin{aligned}
k_{I}\left(-\alpha \nabla_{I}^{2} \theta+\beta \nabla_{I}^{2} S\right)= & \underbrace{k_{I}\left|\nabla_{I} \theta\right|^{2}\left[\frac{\partial \alpha}{\partial \theta}+2 \frac{\alpha}{\beta} \frac{\partial \alpha}{\partial S}+\frac{\alpha^{2}}{\beta^{2}} \frac{\partial \beta}{\partial S}\right]}_{\text {CABBELING }} \\
& +\underbrace{k_{I} \nabla_{I} \theta \cdot \nabla_{I} p\left[\frac{\partial \alpha}{\partial p}-\frac{\alpha}{\beta} \frac{\partial \beta}{\partial p}\right]}_{\text {THERMOBARICITY }} .
\end{aligned}
$$

Cabbeling and thermobaricity are important in several oceanic regions, as discussed in McDougall (1987b) (see also Marsh 2000; You and McDougall 1990; Adkins et al. 2005). From the equation above it is evident that the use of a potential density framework implies an imprecise evaluation of the effect of cabbeling and the impossibility of including the effect of thermobaricity in the transformations.

\section{b. The $b$ factor}

The factor $b$ is a complicated function of $\theta, S, p$, latitude and longitude, and the local gradients of $\theta$ and $S$. From McDougall [(1988); see Eq. (47) and the discussion below Eq. (31) on p. 199 thereof], we find that $b$ varies along neutral trajectories according to

$$
\boldsymbol{\nabla}_{n} \ln b=-k N^{-2}\left(\boldsymbol{\nabla}_{n} \theta-\theta_{z} \boldsymbol{\nabla}_{n} z\right)=-k N^{-2} \nabla_{H} \theta,
$$

where $N$ is the Brunt-Väisälä frequency and $k$ is simply proportional to the thermobaric coefficient $T_{b}$ according to

$$
k \equiv g^{2} \rho T_{b} \approx 2.6 \times 10^{-7} \mathrm{~s}^{-2} \mathrm{~K}^{-1} .
$$

To a good approximation we may replace the surface in which the gradients are taken in (17) from being in the neutral tangent plane to being taken in neutral density surfaces so that it becomes

$$
\boldsymbol{\nabla}_{\gamma} \ln b=-k N^{-2}\left(\boldsymbol{\nabla}_{\gamma} \theta-\theta_{z} \boldsymbol{\nabla}_{\gamma} z\right)=-k N^{-2} \boldsymbol{\nabla}_{H} \theta .
$$

This equation says that the natural logarithm of $b$ varies along a neutral density surface in proportion to the thermobaric nonlinearity of the equation of state and in response to variations of temperature and to variations of the height of the neutral density surface. The particular combination of the epineutral gradients of temperature and height, $\boldsymbol{\nabla}_{\gamma} \theta-\theta_{z} \boldsymbol{\nabla}_{\gamma} z$, is equal to the horizontal temperature gradient $\nabla_{H} \theta$.

An explanation of the need for $b$ to vary spatially can be gleaned by considering the case in which there are no compensating gradients of salinity and temperature along neutral density surfaces so that $\boldsymbol{\nabla}_{\gamma} \theta=0$. In this case, the neutral density surfaces coincide with potential density surfaces. When considering the lateral motion of fluid between pairs of such surfaces, one finds [as proven in section 7.1 of McDougall (1988)] that the vertical integral of $N^{2}$ between the two density surfaces varies in space: an aspect first realized by Veronis (1972). The spatial variation of $b$ as given by (19) is required so that the vertical integral of the product $b N^{2}$ between the two density surfaces does not vary in space; that is, the spatial variation in $b$ has the role of compensating for the less than desirable nature of $N^{2}$, and it is interesting that such compensation is needed even if there are no water-mass variations along the density surfaces.

The variation of the natural logarithm of $b$ is most pronounced in the Southern Ocean. This region is characterized by 1) a significant rise and large variations of the thickness of deep neutral surfaces, which are uplifted and squeezed by the upwelling in the Antarctic divergence (see Fig. 9), and 2) very dense water-mass formation along Antarctica and in the Weddell Sea, which is largely influenced by thermobaricity. Therefore, $b$ is significantly different from unity in the regions of highest surface density and, in general, in regions characterized by the highest density values (Fig. 10). Small deviations from unity also occur along the Subantarctic Front, especially in the Pacific sector of the Southern Ocean.

\section{c. Diagnosis of the transformations occurring in the Southern Ocean}

Using neutral densities instead of potential density implies several differences in the formulation of the water-mass transformations, from taking into account the variation of $\alpha$ and $\beta$ with pressure to the addition of the $b$ factor. To show the impact of the use of neutral densities with respect to potential density in water-mass formation/transformation and of the inclusion of $b$ in the neutral framework, we commence by evaluating the total dianeutral fluxes in the Southern Ocean (here the region south of $30^{\circ} \mathrm{S}$ ) using a long simulation performed with a global ice-ocean model (see appendixes B and C). See Table 1 for a definition of the water masses used in the following; a detailed analysis is presented in Iudicone et al. (2008)]. The choice of this basin is dictated by the occurrence of the largest range of density values that makes the basin the most difficult to be dealt with in standard potential density approaches (e.g., Sloyan and Rintoul 2001).

An overall picture of the transformations in the model Southern Ocean computed via the use of (10) is shown in Fig. (11a), where the mixing and the surface 


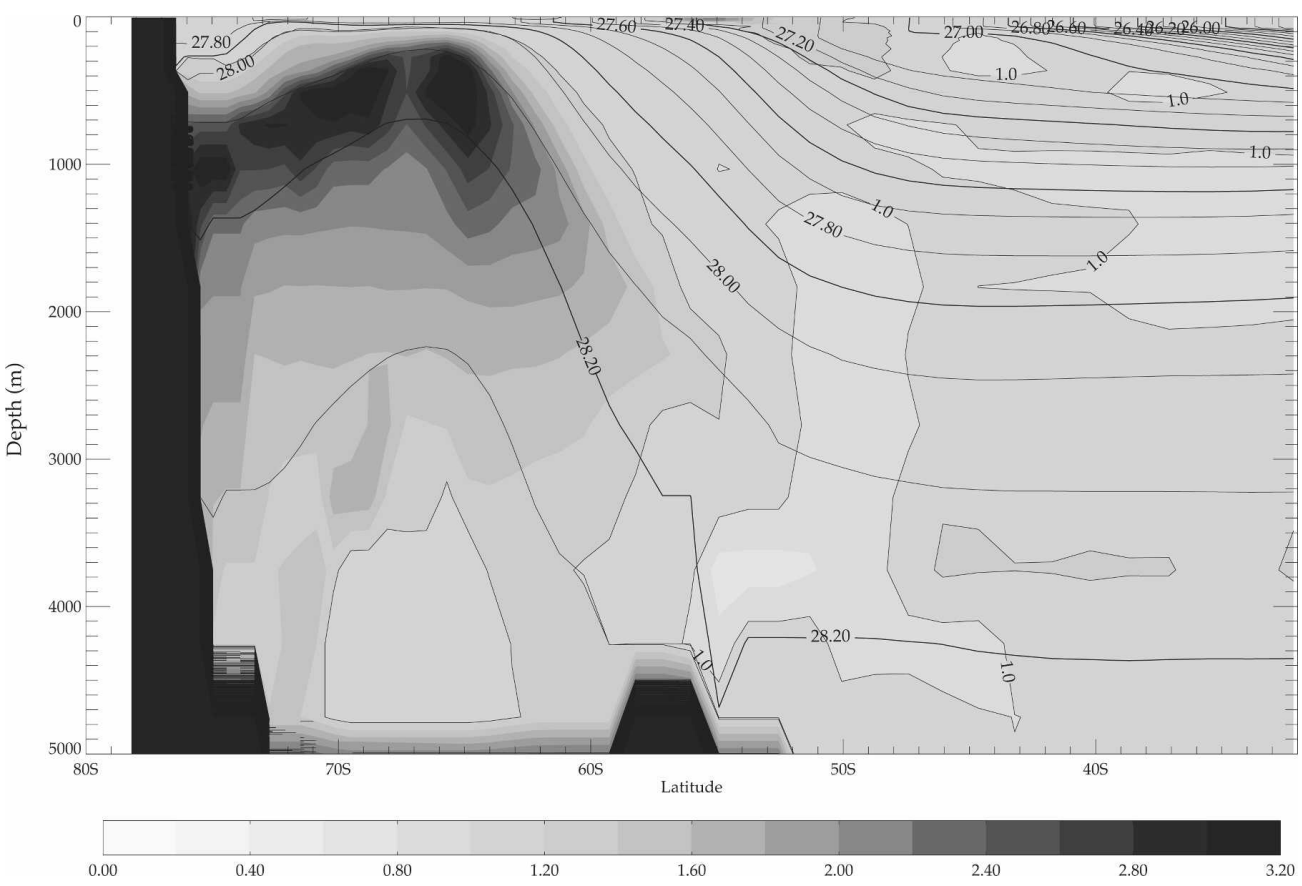

FIG. 9. Meridional section at $222^{\circ} \mathrm{E}$ of the ice-ocean model in austral spring. Neutral density boundaries of the main water masses have been reported. Superimposed is the $b$ field (see Table 1 for water-mass definitions and appendix $\mathrm{C}$ for the model configuration).

fluxes are both included as well as transports through the basin boundaries (see appendix B). The overall distribution of the transport is consistent with observational estimates (e.g., Talley et al. 2003), with discrepancies in the absolute values, the main discrepancy being a weak Upper Circumpolar Deep Water (UCDW)/ Antarctic Bottom Water (AABW) bottom cell [about $10-15 \mathrm{~Sv}$, two to three times smaller than in situ inversions depending on the method; e.g., Sloyan and Rintoul (2001)]. As for the surface fluxes, thermocline and mode water are transformed into denser waters (more

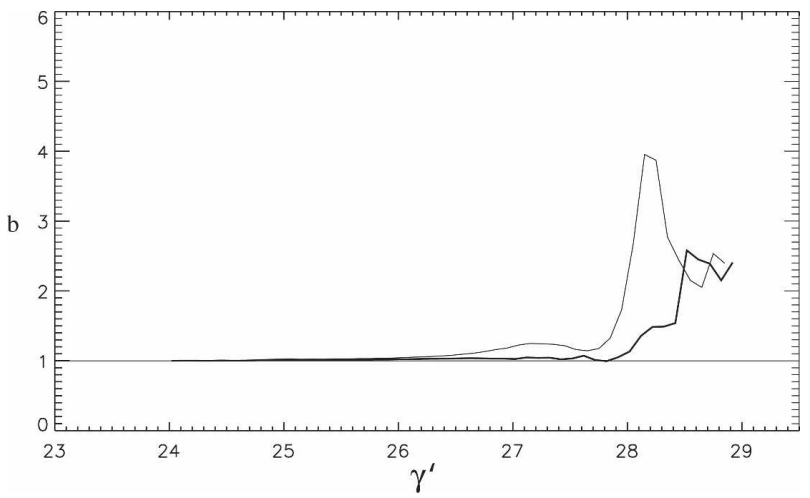

FIG. 10. Volume-averaged $b$ values as a function of neutral density in the Southern Ocean in the model, thick line: total values and thin line: surface values. than $40 \mathrm{~Sv}$ are formed in the class $26.0<\gamma^{\prime}<27.2$ ), while a negative buoyancy input, due to a freshwater excess (not shown), is largely dominating the transformations at higher classes $\left(27.0<\gamma^{\prime}<27.8\right)$. The effect of brine rejection is also noticeable at the highest densities. The overall pattern of surface forcing transformations is consistent with climatologies (e.g., Large and Nurser 2001) and other studies (e.g., Sloyan and Rintoul 2001), apart from the values larger than 28.0 due to the presence of an ice model in our model configuration and not included in the data analysis. Dianeutral and isoneutral mixing tend to densify the water masses (the sign is always positive except for the densest SAMW

TABLE 1. Water mass definitions for the Southern Ocean analysis. Included are STW, MW, IW, UCDW, LCDW, and AABW. Neutral density ranges are generally as in Sloyan and Rintoul (2001). Only the upper limit for IW has been extended to $27.8 \gamma^{\prime}$ after inspection of the characteristics of the simulated water masses.

\begin{tabular}{cc}
\hline Water masses & $\gamma^{\prime}$ \\
\hline STW & $0-26.0$ \\
MW & $26.0-27.2$ \\
IW & $27.2-27.8$ \\
UCDW & $27.8-28.0$ \\
LCDW & $28.0-28.2$ \\
AABW & $28.2-$ bottom
\end{tabular}



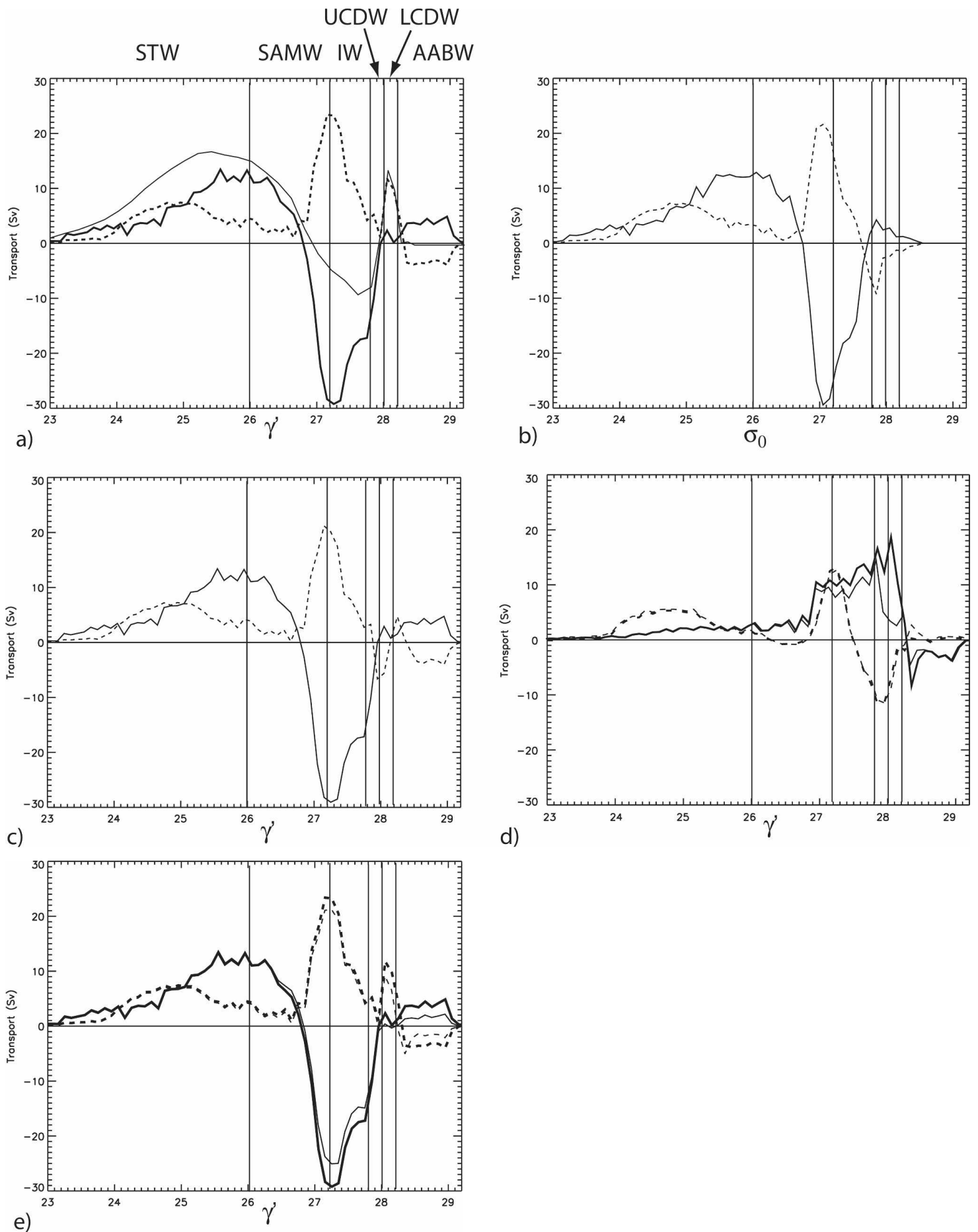

FIG. 11. (a) Total water-mass transformation in the Southern Ocean. The thick line represents the surface buoyancy fluxes; the dashed line the mixing; the thin line the net water-mass transformations $\Omega_{\gamma}$. (b) As in (a) but in a potential density framework. The continuous line represents the surface buoyancy fluxes and the dashed line the mixing. (c) As in (a) but with surface-referenced $\alpha$ and $\beta$. The continuous line represents the surface buoyancy fluxes and the dashed line the mixing. (d) Water mass transformation due to isoneutral mixing (continuous lines) and vertical mixing (dashed lines). The thick lines are the standard values from (10); the dashed lines have been computed using surface-referenced $\alpha$ and $\beta$. Note that the vertical mixing occurs basically close to the surface, which makes the latter much less sensitive to the choice of $\alpha$ and $\beta$. (e) Water mass transformation in the Southern Ocean. The continuous line represents the surface buoyancy fluxes and the dashed lines are for the mixing. The thick lines are as in (a) and the thin lines represent the estimates obtained assuming $b=1$. 
and densest water masses). A large diapycnal transport (net production is $20 \mathrm{~Sv}$ ) is observed for the IW/ UCDW, whose large diapycnal fluxes at the surface are almost completely compensated by internal mixing, finally giving a net budget at $30^{\circ} \mathrm{S}$ of only $3-4 \mathrm{~Sv}$ for the IW. Sloyan and Rintoul (2001) found a similar large transformation of SAMW/IW into UCDW due to mixing $(\sim 31 \mathrm{~Sv})$. At higher densities, the mixing of a large amount of UCDW/Lower Circumpolar Deep Water (LCDW), the peak in the curve at about $28.0 \gamma^{\prime}$ that corresponds to a destruction of about $11 \mathrm{~Sv}$ of dense UCDW and light LCDW and the formation of dense LCDW/AABW, and extremely dense shelf water $(>3 \mathrm{~Sv})$ finally produce AABW (the deepest cell).

The evaluation of the water-mass transformations in the simulated Southern Ocean in a potential density framework is shown in Fig. 11b (see also Marsh et al. 2000). The impact of ocean processes at densities larger than $27 \gamma^{\prime}$ is clearly different. Dense water masses are no longer clearly discernible and the associated transformations are apparently inverted, with a net loss of buoyancy for all water masses denser than $27 \gamma^{\prime}$ (net upwelling). The mismatch between the two approaches is due to the inability of the potential density to discriminate water mass at depth (which are compressed into a shorter density range) and the use of the surfacereferenced $\alpha$ and $\beta$ in the case of the potential density framework (see discussion in section 4a). To evaluate the impact of the latter assumption, implicit in using potential densities, we repeated the assessment of the dianeutral fluxes using (10), as in Fig. 11a, except that we introduced surface-referenced $\alpha$ and $\beta$. As shown in Fig. 11c, the same change of sign in the estimation of mixing in the CDW class and the absence of AABW formation as in Fig. 11b is observed. The decomposition of the water mass transformations due to mixing in Fig. (11a) into vertical and isoneutral mixing (Fig. 11d) shows that, as expected, the nonlinearity of the equation of state affects the isoneutral mixing related to cabbeling and thermobaricity (section 4a).

We finally consider the impact of the $b$ factor alone on our estimates to illustrate how the use of neutral densities indeed requires the estimate of $b$. To evaluate the role of $b$, the estimate of the water mass transformation using (12) has been repeated setting $b=1$ everywhere (Fig. 11e; see also appendix B). In the latter case a mismatch between the two estimates occurs for water with the highest densities $\left(\gamma^{\prime}>27.6\right)$, which actually occupies most of the basin volume.

\section{Conclusions}

In this paper we have presented a generalization of the current method for evaluating water-mass transformation due to boundary forcing and interior mixing. The use of a global density variable, neutral density, allows the classical method of estimating water-mass transformation using surface fluxes (Tziperman 1986) to be extended accurately to the whole oceanic domain. A further development was the inclusion of internal sources of mixing and buoyancy via penetrative fluxes. The method, relatively easy to implement, was tested with encouraging results (noise is relatively small and the estimate of the transports compare positively) for the estimation of water-mass formations/transformations reproduced by an ice-ocean model.

We focused first on the significance of a correct evaluation of the effect of solar radiance in the watermass transformations. The impact of solar shortwave radiation on the water masses below the mixed layer is indeed important, as can be deduced from Fig. 2; this has not previously been considered in quantitative estimates. In fact, the application to the tropics showed that owing to the shallow mixed layer in the regions of upwelling, solar irradiance into the interior can be comparable to vertical diffusion in promoting the transformation of thermocline and mode waters into subsurface waters. It is noteworthy that the term related to solar radiation in (11) can be included in the inversion of in situ data.

The application to the OGCM also showed that the use of a neutral density framework is necessary when dealing with the analysis of thermodynamics of the global thermohaline circulation. Finally, the value of $b$ has to be carefully estimated, and we propose the use of horizontal gradients as an efficient and relatively simple approach to evaluate $b$, an approach that is suitable also for the mixed layer.

Acknowledgments. The authors thank Dr. Lynne Talley and the two anonymous reviewers for their most constructive and knowledgeable comments.

This work is funded in part by the Programe National d'Etude du Climate (PNEDC) and CANOPO PEA. This work contributes to the CSIRO Climate Change Research Program.

\section{APPENDIX A}

\section{The Material Derivative of Neutral Density}

In McDougall and Jackett (2005) it was shown that the material derivative of neutral density $\gamma$ is given by 


$$
\begin{aligned}
d \ln \gamma / d t \approx & -b \frac{1}{2} T_{b} F\left(\theta-\theta^{r}\right) \dot{p}-b \frac{1}{2} T_{b} F\left[\left(\theta-\theta^{r}\right) \mathbf{V} \cdot \nabla_{\gamma} p^{r}-\left(p-p^{r}\right) \mathbf{V} \cdot \nabla_{\gamma} \theta^{r}\right]-b g^{-1} N^{2} \mathbf{V} \cdot \mathbf{s} \\
& -b\left[g^{-1} N^{2}-\frac{1}{2} \rho g T_{b} F\left(\theta-\theta^{r}\right)\right] \frac{(a(\bar{p}) \dot{\theta}-\beta(\bar{p}) \dot{S})}{\left(a(\bar{p}) \theta_{z}^{r}-\beta(\bar{p}) S_{z}^{r}\right)},
\end{aligned}
$$

where $F$ is defined by

$$
F=\left\{1+\frac{1}{2} T_{b} \rho g^{2} N^{-2}\left[\left(\theta-\theta^{r}\right)-\left(p-p^{r}\right) \theta_{p}^{r}\right]\right\}^{-1}
$$

and the third line and the $\mathbf{V} \cdot \mathbf{S}$ term in (A1) is due to the scalar product of the horizontal velocity $\mathbf{V}$ and the difference in slope between the neutral tangent plane and the neutral density surface in the labeled reference dataset, $\mathbf{s} \equiv \boldsymbol{\nabla}_{n} z^{r}-\boldsymbol{\nabla}_{\gamma} z^{r}$. In McDougall and Jackett (1988), it was shown that this contribution to (A1) is particularly small. Here $T_{b}$ is the thermobaric parameter, $T_{b}=\beta \partial(\alpha / \beta) / \partial p \approx 2.7 \times 10^{-12} \mathrm{~K}^{-1} \mathrm{~Pa}^{-1}$, defined in terms of the variation of the thermal expansion coefficient $\alpha$ and saline contraction coefficient $\beta$ with pressure.
In (A1) $\left(\theta-\theta^{r}\right)$ and $\left(p-p^{r}\right)$ are the differences in potential temperature and pressure between a parcel's potential temperature and pressure and those of the labeled dataset [of Jackett and McDougall's (1997) neutral density algorithm] that are neutrally related to the parcel; that is, the parcel $(S, \theta, p)$ and the datum $\left(S^{r}, \theta^{r}, p^{r}\right)$ in the labeled dataset have the same density when moved adiabatically and isentropically to the average pressure $\bar{p}=0.5\left(p+p^{r}\right)$. For reasonable values of $\left(\theta-\theta^{r}\right)$ and $\left(p-p^{r}\right)$ (such as, say, $2^{\circ} \mathrm{C}$ and 150 dbar) the factor $F$ is close to unity and the first bracket pair in the last line of (A1) can be approximated by $g^{-1} N^{2}$.

The first two terms in (A1) take values of the same order in the ocean, and as a fraction of the last term of (A1) these terms are typically

$$
\frac{\text { first two terms of }(\mathrm{A} 1)}{\text { last term of }(\mathrm{A} 1)} \approx O\left(\frac{\frac{1}{2} T_{b}\left(p-p^{r}\right) \mathbf{V} \cdot \nabla_{\gamma} \theta^{r}}{a(\bar{p}) \dot{\theta}}\right) \approx O\left(\frac{\frac{1}{2} T_{b}\left(p-p^{r}\right)}{a(\bar{p})}\right) \approx 0.01
$$

where we note that $a(\bar{p}) \theta_{z}^{r}-\beta(\bar{p}) S_{z}^{r}$ is similar to $g^{-1} N^{2}$ and $\mathbf{V} \cdot \nabla_{\gamma} \theta^{r} \approx O(\dot{\theta})$. The last part of (A3) uses typical values of the thermal expansion coefficient and of the pressure difference of $2 \times 10^{-4} \mathrm{~K}^{-1}$ and $150 \mathrm{dbar}(1.5$ $\mathrm{MPa})$, respectively. Hence we conclude that for many purposes we may approximate (A1) by the simpler expression [see also Eq. (5) of McDougall (1995)]

$$
d \ln \gamma / d t \approx-b(a \dot{\theta}-\beta \dot{S})=b d \ln \rho / d t,
$$

where $\alpha$ and $\beta$ are evaluated at the local pressure and $\rho$ is the locally referenced potential density.

\section{APPENDIX B}

\section{Discretization and Implementation}

Here we describe the practical method to compute the total dianeutral transport across neutral density surfaces due to both interior mixing processes and surface buoyancy fluxes. Briefly, we will develop an expression for net transformations [see (10)]. As discussed in section 3 , the method examines the evolution equation of neutral density via the tendencies of potential tempera- ture and salinity; thus, the key point is to evaluate these latter terms.

First we note that

$$
\begin{aligned}
\Omega_{\gamma} & =\frac{\partial}{\partial \gamma} \iint_{V_{\gamma}} \gamma b\left(d_{\rho}+f_{\rho}\right) d v \\
& =\lim _{\Delta \gamma \rightarrow 0} \frac{1}{\Delta \gamma} \iiint_{V_{\gamma}} \gamma b\left(d_{\rho}+f_{\rho}\right) d v, \\
& =\iint_{V_{\gamma}} \gamma b\left(d_{\rho}+f_{\rho}\right) \delta_{\gamma^{\prime}=\gamma} d v .
\end{aligned}
$$

Dividing the domain of interest into grid boxes $(i, j$, $k$ ) and integrating $F+D$ over small volumes $V_{i, j, k}$, we have

$$
\iint_{V_{\gamma}} \int_{\rho} \gamma b\left(d_{\rho}+f_{\rho}\right) d v=\left[\overline{\gamma b\left(d_{\rho}+f_{\rho}\right)}\right]_{i, j, k} V_{i, j, k}
$$

With further integration on finite density intervals $\Delta \gamma$, the integral on the right in (10) can then be rewritten as 


$$
\Omega_{\gamma} \sim \frac{1}{\Delta \gamma} \sum_{i, j, k}\left[\overline{\gamma b\left(d_{\rho}+f_{\rho}\right)}\right]_{i, j, k} V_{i, j, k} \Pi_{\gamma-\gamma^{\prime}}
$$

where $\Pi_{\gamma-\gamma^{\prime}}$ is the boxcar function $\Pi_{\gamma-\gamma^{\prime}}=1$ for

$$
\gamma-\frac{\Delta \gamma}{2}<\gamma^{\prime} \leq \gamma+\frac{\Delta \gamma}{2}
$$

In practice, we evaluate the irreversible production of "density" in the above equations by examining the corresponding production terms of potential temperature and salinity via (4). Each term in (B1) is thus easily evaluated from the tendencies of $\theta$ and $S$ (by substituting the terms in brackets, as discussed above), via the locally referenced expansion coefficients [see Eq. (A4) in appendix A]. We remind one here that (B1) does not imply the projection of the forcing and mixing terms on the neutral surface and that the standard Cartesian projection can be used.

Finally, for the diffusive flux terms, the formula derived here uses the same mathematical formalism of Marshall et al. (1999; see their appendix for a thorough discussion), with the additional feature that we include the factor $b=|\nabla \gamma| /|\nabla \rho|$, which needs a further effort in the computation (see below). Entrainment/detrainment processes are naturally included if a prognostic treatment is used for static instabilities (e.g., higher diffusivity). A separate diagnostic has to be used instead when dealing with convective adjustment algorithms.

\section{The implementation of the method for the ocean model outputs}

Once the tendency terms for temperature and salinity are stored, the implementation of (12) via (B1) is straightforward, with the exception of the $b$ factor that has no state equation and has to be estimated empirically, as discussed in section 4. Its estimate is, in fact, quite tricky because of the noise in the direct computation. After several tests, we have chosen to estimate $b$ by taking the local average of the horizontal ratio $\Delta \gamma /$ $\Delta \rho$ in every grid point and for every model output. This avoids problems in the mixed layer. In the end, an annual mean $b$ field was derived. The time-averaging procedure considerably reduced the noise in the estimate at the expenses of neglecting the seasonal variability.

To validate the application of the new formulation to the ocean model, we computed the budget of transformations for the Southern Ocean, here bounded to the north by $30^{\circ} \mathrm{S}$, where $b$ can be greater than unity. As a first check for the correct implementation of the methodology and of the steadiness of the ocean simulation, the residuals of all the terms of the neutral density equation [i.e., the terms in (10) minus the advection

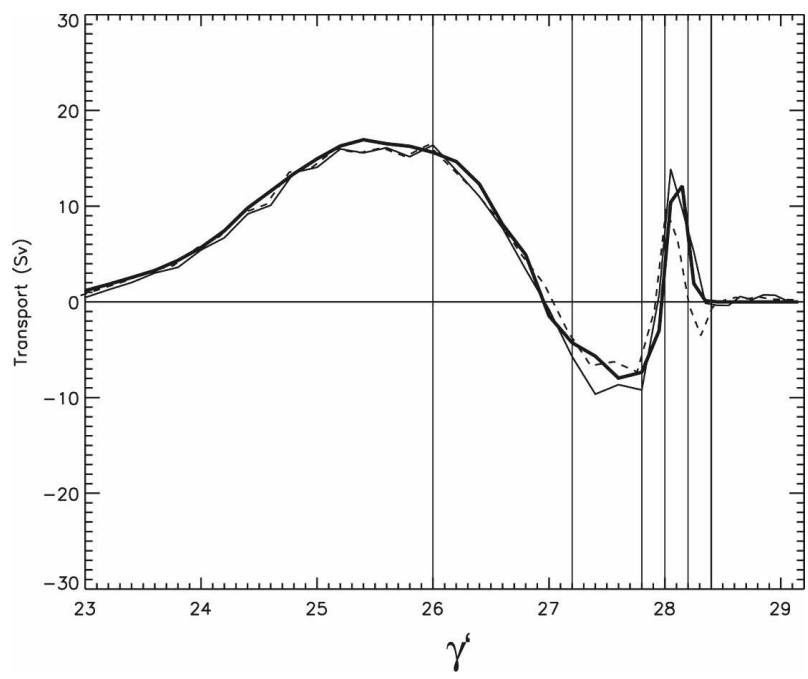

Figure B1. Plot of $-\left(\Psi_{\gamma}+E_{\gamma}\right)$ (thick line) in terms of neutral density. The thin continuous line represents the sum of the advective terms computed as in (12). The thin dashed line is also the sum of the advective terms but in the case of $b=1$. Bin size has been doubled for values less than $27.8 \gamma^{\prime}$ to eliminate the noise in the surface flux discretization.

terms] have been computed (not shown). The overall sum is zero (there is no net residual), but some noise exists at intermediate densities when considering the residual decomposed into neutral density classes. The source of the noise is in the discretization of density values due to the use of time mean values for the tendencies and to the finite number of grid points; that is, the bin size is too small in some cases. These issues are significant, essentially for the computation of the surface heat fluxes.

The assumption of steady state implies that (11) becomes $\Psi_{\gamma}+E_{\gamma}=-\Omega_{\gamma}$, where

$$
\Psi_{\gamma}+E_{\gamma}=\int_{\gamma_{\max }}^{\gamma} \phi\left(\gamma^{\prime}\right) d \gamma^{\prime}+\int_{\gamma_{\max }}^{\gamma} e\left(\gamma^{\prime}\right) d \gamma^{\prime}
$$

and $\phi\left(\gamma^{\prime}\right)$ and $e\left(\gamma^{\prime}\right)$ are the volume transports (as function of neutral density) at $30^{\circ} \mathrm{S}$ and at the surface, respectively.

In Fig. B1 the values of $-\left(\Psi_{\gamma}+E_{\gamma}\right)$, decomposed into the same density classes as $\Omega_{\gamma}$, are compared to $\Omega_{\gamma}$. The superposition of the two curves is rather good. The main discrepancies occur at about 27.3-27.6 $\gamma^{\prime}$ and 28.0 $\gamma^{\prime}$, due to both the binning on finite-size bins and the noise in the estimate of the $b$ factor.

We finally consider the impact of the $b$ factor alone on our estimates to illustrate how the use of neutral densities indeed requires the estimate of $b$. In the latter case a mismatch between the two estimates occurs for water with the highest densities $\left(\gamma^{\prime}>27.6\right)$, water that 
actually occupies most of the basin volume (Fig. B1). The estimate of the surface forcing for densities close to $27.3 \gamma^{\prime}$ is also sensitive to the use of $b$, and it is actually improved if $b=1$ is used for these water masses. As discussed in section $4 \mathrm{~b}$, the $b$ term is larger than unity along the subpolar front, with values particularly large (1.2-1.4) in the South Pacific sector of the Southern Ocean. This latter point is rather puzzling and remains unexplained.

\section{APPENDIX C}

\section{The Ice-Ocean Coupled Model}

The method has been applied to the final year of a 1500 -yr simulation of a state-of-the-art global ice-ocean coupled system (ORCA2-LIM; see Madec 1999; Timmermann et al. 2005; Iudicone et al. 2008); the model includes a parameterization of eddy transport and isoneutral diffusion and bottom boundary layer diffusion of tracers. Surface forcings are included via the use of the bulk formulae, which include a penetrative formulation for the solar shortwave radiation (the same as in Manizza et al. 2005). A geothermal flux is also imposed at the bottom. The model has virtually reached a steady state and has realistic tracer and transport values (Iudicone et al. 2008). Mean model tendencies for $\theta$ and $S$ have been stored every 14.3 days, and neutral density computed via the Jackett and McDougall (1997) routines.

\section{REFERENCES}

Adkins, J. F., A. P. Ingersoll, and C. Pasquero, 2005: Rapid climate change and conditional instability of the glacial deep ocean from the thermobaric effect and geothermal heating. Quat. Sci. Rev., 24, 581-594.

Blanke, B., S. Speich, G. Madec, and K. Döös, 2001: A global diagnostic of interocean mass transfers. J. Phys. Oceanogr., 31, 1623-1632.

,$--\longrightarrow$, and R. Maugé, 2002: A global diagnostic of interior ocean ventilation. Geophys. Res. Lett., 29, 1267, doi:10.1029/2001GL013727.

de Boyer Montégut, C., G. Madec, A. S. Fischer, A. Lazar, and D. Iudicone, 2004: Mixed layer depth over the global ocean: An examination of profile data and a profile-based climatology. J. Geophys. Res., 109, C12003, doi:10.1029/2004JC002378.

Donners, J., S. S. Drijfhout, and W. Hazeleger, 2005: Water mass transformation and subduction in the South Atlantic. J. Phys. Oceanogr., 35, 1841-1860.

D’Ortenzio, F., D. Iudicone, C. de Boyer Montégut, P. Testor, D. Antoine, S. Marullo, R. Santoleri, and G. Madec, 2005: Seasonal variability of the mixed layer depth in the Mediterranean Sea as derived from in situ profiles. Geophys. Res. Lett., 32, L12605, doi:10.1029/2005GL022463.

Dutay, J.-C., G. Madec, P. Jean-Baptiste, and D. Iudicone, 2003: Study of the impact of the geothermal heating on ORCA model deep circulation deduced from natural helium-3 simu- lations. Geophysical Research Abstracts, Vol. 5, Abstract 06282. [Available online at http://www.cosis.net/abstracts/ EAE03/06282/EAE03-J-06282.pdf.]

Fine, R. A., K. A. Maillet, K. F. Sullivan, and D. Willey, 2001: Circulation and ventilation flux of the Pacific Ocean. J. Geophys. Res., 106, 22 159-22 178.

Garrett, C., K. Speer, and E. Tragou, 1995: The relationship between water mass formation and the surface buoyancy flux, with application to Phillips' Red Sea model. J. Phys. Oceanogr., 25, 1696-1705.

Gill, A. E., 1982: Atmosphere-Ocean Dynamics. Academic Press, $662 \mathrm{pp}$.

Hanawa, K., and L. D. Talley, 2001: Mode waters. Ocean Circulation and Climate: Observing and Modelling the Global Ocean, G. Siedler, J. Church, and J. Gould, Eds., International Geophysics Series, Vol. 77, Academic Press, 373-386.

Hazeleger, W., P. de Vries, and G. J. van Oldenborgh, 2001: Do tropical cells ventilate the Indo-Pacific equatorial thermocline? Geophys. Res. Lett., 28, 1763-1766.

Iudicone, D., G. Madec, B. Blanke, and S. Speich, 2008: The role of Southern Ocean surface forcings and mixing in the global conveyor. J. Phys. Oceanogr., 38, 1377-1400.

Jackett, D. R., and T. J. McDougall, 1997: A neutral density variable for the world's oceans. J. Phys. Oceanogr., 27, 237-263.

Large, W. G., and A. J. G. Nurser, 2001: Ocean surface water mass transformation. Ocean Circulation and Climate: Observing and Modelling the Global Ocean, G. Siedler, J. Church, and J. Gould, Eds., International Geophysics Series, Vol. 77, Academic Press, 317-336.

Madec, G., P. Delecluse, M. Imbard, and C. Lévy, 1999: OPA 8.1 ocean general circulation model reference manual. Notes du Pôle de modélisation, Institut Pierre-Simon Laplace, Paris, France, $91 \mathrm{pp}$.

Manizza, M., C. Le Quéré, A. J. Watson, and E. T. Buitenhuis, 2005: Bio-optical feedbacks among phytoplankton, upper ocean physics and sea-ice in a global model. Geophys. Res. Lett., 32, L05603, doi:10.1029/2004GL020778.

Marsh, R., 2000: Cabbeling due to isopycnal mixing in isopycnic coordinate models. J. Phys. Oceanogr., 30, 1757-1775.

_ A. J. G. Nurser, A. P. Megann, and A. L. New, 2000: Water mass transformation in the Southern Ocean of a global isopycnal coordinate GCM. J. Phys. Oceanogr., 30, 1013-1045.

Marshall, J., A. J. G. Nurser, and R. G. Williams, 1993: Inferring the subduction rate and period over the North Atlantic. $J$. Phys. Oceanogr., 23, 1315-1329.

_ D. D. Jamous, and J. Nilsson, 1999: Reconciling thermodynamic and dynamic methods of computation of water-mass transformation rates. Deep-Sea Res. I, 46, 545-572.

Marzeion, B., A. Timmermann, R. Murtugudde, and F.-F. Jin, 2005: Biophysical feedbacks in the tropical Pacific. J. Climate, 18, 58-70.

McDougall, T. J., 1984: The relative roles of diapycnal and isopycnal mixing on subsurface water mass conversion. J. Phys. Oceanogr., 14, 1577-1589.

_- 1987a: Neutral surfaces. J. Phys. Oceanogr., 17, 1950-1964. , 1987b: Thermobaricity, cabbeling, and water-mass conversion. J. Geophys. Res., 92, 5448-5464.

_ 1988: Neutral-surface potential vorticity. Prog. Oceanogr., 20, 185-221.

_ 1995: The influence of ocean mixing on the absolute velocity vector. J. Phys. Oceanogr., 25, 705-725.

- and D. R. Jackett, 1988: On the helical nature of neutral trajectories in the ocean. Prog. Oceanogr., 20, 153-183. 
and - 2005: The material derivative of neutral density. $J$. Mar. Res., 63, 159-185.

Miller, A. J., and Coauthors, 2003: Potential feedbacks between Pacific Ocean ecosystems and interdecadal climate variations. Bull. Amer. Meteor. Soc., 84, 617-633.

Mobley, C. D., 1994: Light and Water: Radiative Transfer in Natural Waters. Academic Press, 592 pp.

Nurser, A. J. G., R. Marsh, and R. G. Williams, 1999: Diagnosing water mass formation from air-sea fluxes and surface mixing. J. Phys. Oceanogr., 29, 1468-1487.

Ohlmann, J. C., and D. A. Siegel, 2000: Ocean radiant heating. Part II: Parameterizing solar radiation transmission through the upper ocean. J. Phys. Oceanogr., 30, 1849-1865.

$\_,-$, and C. Gautier, 1996: Ocean mixed layer radiant heating and solar penetration: A global analysis. J. Climate, 9, 2265-2280.

Schott, F. A., J. P. McCreary Jr., and G. C. Johnson, 2004: Shallow overturning circulations of the tropical-subtropical oceans. Earth's Climate: The Ocean-Atmosphere Interaction, Geophys. Monogr., Vol. 147, Amer. Geophys. Union, 261-304.

Scott, J. R., J. Marotzke, and A. Adcroft, 2001: Geothermal heating and its influence on the meridional overturning circulation. J. Geophys. Res., 106, 31 141-31 154.

Siegel, D. A., J. C. Ohlmann, L. Washburn, R. R. Bidigare, C. T. Nosse, E. Fields, and Y. Zhou, 1995: Solar radiation, phytoplankton pigments and the radiant heating of the equatorial Pacific warm pool. J. Geophys. Res., 100, 4885-4891.

Sloyan, B. M., and S. R. Rintoul, 2001: The Southern Ocean limb of the global deep overturning circulation. J. Phys. Oceanogr., 31, 143-173.

—, G. C. Johnson, and W. S. Kessler, 2003: The Pacific cold tongue: A pathway for interhemispheric exchange. J. Phys. Oceanogr., 33, 1027-1043.
Speer, K., and E. Tziperman, 1992: Rates of water mass formation in the North Atlantic Ocean. J. Phys. Oceanogr., 22, 93-104.

— H. H. Isemer, and A. Biastoch, 1995: Water mass formation from revised COADS data. J. Phys. Oceanogr., 25, 2444 2457.

Stommel, H., 1979: Determination of water mass properties of water pumped down from the Ekman layer to the geostrophic flow below. Proc. Natl. Acad. Sci. USA, 76, 30513055 .

Talley, L. D., J. L. Reid, and P. E. Robbins, 2003: Data-based meridional overturning streamfunctions for the global ocean. J. Climate, 16, 3213-3226.

Timmermann, R., H. Goosse, G. Madec, T. Fichefet, C. Ethe, and V. Duliere, 2005: On the representation of high latitude processes in the ORCA-LIM global coupled sea ice-ocean model. Ocean Modell., 8, 175-201.

Tziperman, E., 1986: On the role of interior mixing and air-sea fluxes in determining the stratification and circulation of the oceans. J. Phys. Oceanogr., 16, 680-693.

Veronis, G., 1972: On properties of seawater defined by temperature, salinity, and pressure. J. Mar. Res., 30, 227-255.

Viúdez, A., 2000: Volume and mass transport across isosurfaces of a balanced fluid property. J. Phys. Oceanogr., 30, 1478-1485.

Walin, G., 1982: On the relation between sea-surface heat flow and thermal circulation in the ocean. Tellus, 34, 187-195.

Wunsch, C., and R. Ferrari, 2004: Vertical mixing, energy, and the general circulation of the oceans. Annu. Rev. Fluid Mech., 36, 281-314

You, Y., and T. J. McDougall, 1990: Neutral surfaces and potential vorticity in the world's oceans. J. Geophys. Res., 95, $13235-13261$. 